\title{
YERBILIMLERI
}

Bulletin for Earth Sciences

Yerbilimleri, 2019, 40 (3), 293-325, DOI: 10.17824/yerbilimleri.633036

Hacettepe Üniversitesi Yerbilimleri Uygulama ve Araştırma Merkezi Bülteni

Bulletin of the Earth Sciences Application and Research Centre of Hacettepe University

\section{Zigana Dağı (Gümüşhane, KD Türkiye) Dayklarının Jeokimyası ve Jeolojik}

\section{Anlamı}

Geochemistry of the Zigana Mountain (Gümüşhane, NE Turkey) Dykes and Their Geological Meaning

\section{FERKAN SIPAHI " ${ }^{*}$, MEHMET ALI GÜCER ${ }^{1}$, MÜNÜR BURHAN SADIKLAR ${ }^{2}$ \\ 1 Gümüşhane Üniversitesi Mühendislik ve Doğa Bilimleri Fakültesi Jeoloji Mühendisliği Bölümü, 29100 Gümüşhane \\ 2 Karadeniz Teknik Üniversitesi Mühendislik Fakültesi, Jeoloji Mühendisliği Bölümü, 61080 Trabzon}

Geliş (received): 15Ekim (October) 2019

Kabul (accepted) : 5 Aralık (December) 2019

Öz

Eski bir magmatik yay olan Doğu Karadeniz Bölgesi (Pontidler) Sakarya Zonu içinde yer alan andezit ve porfirik dasit daykları Geç Kretase yaşıı volkanitleri kesmektedir. Andezit ve porfirik dasit daykları porfirik doku sergilemektedir. Andezitler başlıca plajiyoklas ve ojit minerallerinden ibaret olup, plajiyoklaslar elek dokusu ve polisentetik ikizlenme göstermektedir. Ojit minerallerinin kenar kısımlarında opak mineral oluşumları yaygındır. Porfirik dasitler ise kuvars, plajiyoklas, amfibol ve biyotit minerallerinden oluşmakta olup, kuvars kristallerinin kenarları kısmen yenmiştir. Plajiyoklaslar yaygın olarak serizitleşmiş, daha az oranda kalsitleşmiştir. Amfiboller hidrotermal ayrışma sonucu klorit, karbonat (kalsit ve ankerit) ve opak minerallere, biyotitler ise genel olarak kloritlere dönüşmüştür. Ana oksit ve iz element değişim diyagramlarındaki düzgün yönsemeleri ve mineral ayrımlaşma diyagramlarındaki 
durumları, daykların gelişiminde fraksiyonel kristalleşmenin etkili olduğunu göstermektedir. Plajiyoklas ve ojit ayrımlaşmasının andezit daykların gelişiminde, hornblend ve plajiyoklas ayrımlaşmasının ise porfirik dasitlerin gelişiminde etkili olduğu belirlenmiştir. Zenginleşmiş okyanus ortası sırtı bazaltlara (Z-OOSB) göre normalleştirilmiş iz element diyagramında negatif $\mathrm{Nb}, \mathrm{P}_{2} \mathrm{O}_{5}$ ve $\mathrm{TiO}_{2}$ anomalileri olup, büyük iyon çaplı elementler (BIYYE) yüksek çekim alanlı elementlere (YÇAE) nazaran daha fazla zenginleşmiştir. Düşük $\mathrm{Nb} / \mathrm{U}$ ile yüksek $\mathrm{La} / \mathrm{Nb}$ ve $\mathrm{Th} / \mathrm{Nb}$ oranları, andezit ve porfirik dasit dayklarının kıtasal kabuk kirlenmesinden etkilendiğini belirtmektedir. Sonuç olarak, daykların yay ortamında, Geç Kretase sonlarına doğru benzer kökenli ve yitim ilişkili metasomatize olmuş bir manto kaynağından türemiş oldukları düşünülmektedir.

Anahtar Kelimeler: Dayk, Zigana (Gümüşhane), Geç Kretase, Jeokimya, KD-Türkiye.

\section{ABSTRACT}

The andesite and porphyritic dacite dykes in the Sakarya Zone of the Eastern Black Sea Region (Pontides), an ancient magmatic arc, cut through the Late Cretaceous volcanic rocks. Andesite and porphyritic dacite dykes show porphyritic texture. Andesites consist mainly of plagioclase and augite minerals and plagioclases show sieve texture and polysynthetic twinning. Opaque mineral formations are common on the marginal parts of augite minerals. Porphyritic dacites consist of quartz, plagioclase, amphibole and biotite minerals and the edges of quartz crystals are partially corroded. Plagioclases are commonly sericitized and less calcitized. As a result of hydrothermal alteration, amphibole decomposed to chlorite, carbonate (calcite and ankerite) and opaque minerals, and biotite to chlorite. The uniform orientations in the main oxide and trace element exchange diagrams and the states in the mineral separation diagrams show that fractional crystallization is effective in the development of dykes. It was determined that plagioclase and augite differentiation was effective in the development of andesite dykes, and hornblende and plagioclase differentiation in the development of porphyritic dacites. In the normalized trace element diagram according to enriched mid-ocean ridge basalts (E-MORB), there are negative $\mathrm{Nb}, \mathrm{P}_{2} \mathrm{O}_{5}$ and $\mathrm{TiO}_{2}$ anomalies, and large ion-diameter elements (LILE) are more enriched than high-gravity elements (HFSE). LowNb/U and high $\mathrm{La} / \mathrm{Nb}$ and $\mathrm{Th} / \mathrm{Nb}$ ratios indicate that andesite and porphyritic dacite dykes are affected by continental crust contamination. As a result, it 
is thought that the dikes are derived from a metasomatized mantle source, a similar origin and related to subduction, towards the end of Late Cretaceous in the arc environment.

Keywords: Dyke, Zigana (Gümüşhane), Late Cretaceous, geochemistry, NE-Turkey.

\section{GíRiş}

Zigana Dağı (Gümüşhane), Türkiye'nin kuzeydoğusunda, Alp-Himalaya Dağ silsilesinin üzerinde olan Doğu Karadeniz Dağları üzerinde bulunmaktadır. Doğu Karadeniz Bölgesi (Doğu Pontidler) zengin maden yatakları içermesi, tektoniği ve jeolojisi açısından günümüze kadar bir çok araştırmacının (Adamia vd., 1977; Pejatoviç, 1979; Şengör ve Yılmaz, 1981; Özsayar vd., 1981; Akıncı, 1984; Bektaş vd., 1984; Dokuz, 2011; Sipahi, 2011, 2017, 2019; Sipahi ve Sadıklar, 2010, 2014 Saydam Eker vd., 2012; Sipahi vd., 2014, 2017, 2018; Kaygusuz vd., 2013, 2014, 2016; Aydınçakır, 2016; Gücer vd., 2017; vs.) ilgisini çekmiştir. Jura'dan Tersiyer'e kadar etkin denizaltı volkanizmasıyla karakterize bir ada yayı özelliği gösteren bölge, volkanizma eşlikli masif sülfit, porfiri bakır, epitermal damar ve skarn tipte maden yatakları içermektedir (Sipahi ve Sadıklar, 2010; Sipahi, 2011, 2019; Eyüboğlu vd., 2014; Akaryalı, 2016; Akbulut ve Akaryalı, 2016; Sipahi vd., 2017). Doğu Karadeniz Bölgesi'nde Karbonifer'den Eosen'e kadar değişik seviyelerdeki magmatik kayaçları kesen çok sayıda dayklar bulunmakla birlikte, bunlar şimdiye kadar sadece petrografik olarak incelenmiş olup jeokimyasal olarak ele alınmamıştır. Dolayısıyla bölgede bulunan daykların jeokimyasal anlamı ve önemi araştırılmamıştır.

Zigana Dağı ve civarında yüzlek veren Geç Kretase yaşlı volkanitler (bazalt, andezit, dasit-I ve dasit-II) çok sayıda dayk tarafından kesilmekte olup, genellikle dasit ve andezit bileşimlidir. Bu çalışma kapsamında, Geç Kretase yaşlı volkanitleri kesen dayklar, jeokimyasal olarak irdelenmiş ve bölgenin jeolojik evrimindeki yerinin araştıııması hedeflenmiş̧ir. 


\section{BÖLGENIN VE ÇALIŞMA ALANININ JEOLOJISi}

Eski bir magmatik yayı temsil eden Doğu Karadeniz Bölgesi (Pontidler), Sakarya Zonu içinde yer almaktadır (Okay ve Tüysüz, 1999). Pontidler, Jura öncesi temel birimlerdeki farklılıklara göre batı, orta ve doğu olmak üzere üç kısma ayrılmaktadır (Şengör ve Yılmaz, 1981; Şekil 1). Alpin orojenezi süresince Torid-Anatolid ile Avrasya plakasının çarpışmasından etkilenmiş olan bölge, Neo-Tetisin kenarları boyunca gelişen magmatizmanın izlerini taşımaktadır (Şengör ve Yılmaz, 1981). Doğu Pontidler farklı magmatik, tektonik ve sedimantolojik evrim aşamalarına göre kuzeyden güneye doğru Kuzey, Güney ve Eksen zonları olmak üzere üç alt birliğe ayrılmıştır (Bektaş vd., 1995). Bölgede ilki Erken Jura'da başlayan ve bazik volkanitleri oluşturan üç ana volkanik evre ayırt edilmiştir (Arslan vd., 1997). Çalışma alanını da içine alan Kuzey zon genellikle Geç Kretase (Arslan vd., 1997; Sipahi, 2005, 2017; Kaygusuz vd., 2014; Sipahi ve Sadıklar, 2014; Sipahi vd., 2014, 2018), Eosen (Arslan vd., 1997; Temizel vd., 2012; Aydınçakır, 2014; Sipahi vd., 2017; Gücer vd., 2017) ve Neojen (Aydın vd., 2008) kayaçları ile temsil edilmekle birlikte, bu zonun temel birimlerini, küçük mostralar halinde yüzlek veren, Karbonifer yaşlı granitoidler oluşturmaktadır (Kaygusuz vd.,2012, 2016). Liyas'dan Erken Kretase sonuna kadar devam eden bazik volkanizmanın ürünleri granitik kayaçlar tarafından kesilmektedir. Liyas yaşlı kayaçlar üzerinde, Geç Jura - Erken Kretase yaşlı karbonatlar (Berdiga Formasyonu) mercek ya da iri bloklar şeklinde bulunmaktadır. Doğu Karadeniz'in Kuzey ve Güney zonlarında, Kretase süresince stratigrafi ve magmatizma açısından bazı farklııklar belirtilmekte olup, Kuzey zonda özellikle magmatitler yaygın iken, Güney zonda genellikle sedimanter kayaçlar egemenlik sunmaktadır (Bektaş vd., 1984).

Zigana Dağı civarında Geç Kretase yaşı birimler genellikle bazalt, andezit ve dasitlerden oluşmaktadır. Bimodal karakterde ve volkanik yay ortamlarında gelişmiş dasitler dasit-I (illit: $78.7 \pm 2.3 \mathrm{My}$ ) ve dasit-II (illit: $75.3 \pm 2.4 \mathrm{My}$ ) olarak adlandırılımıştır (Sipahi, 2005; Sipahi ve Sadıklar, 2014). Geç Kretase sonlarına doğru volkanitler, iri kuvarsı porfirik dasit ve andezit daykları tarafından kesilmektedir (Şekil 2). 


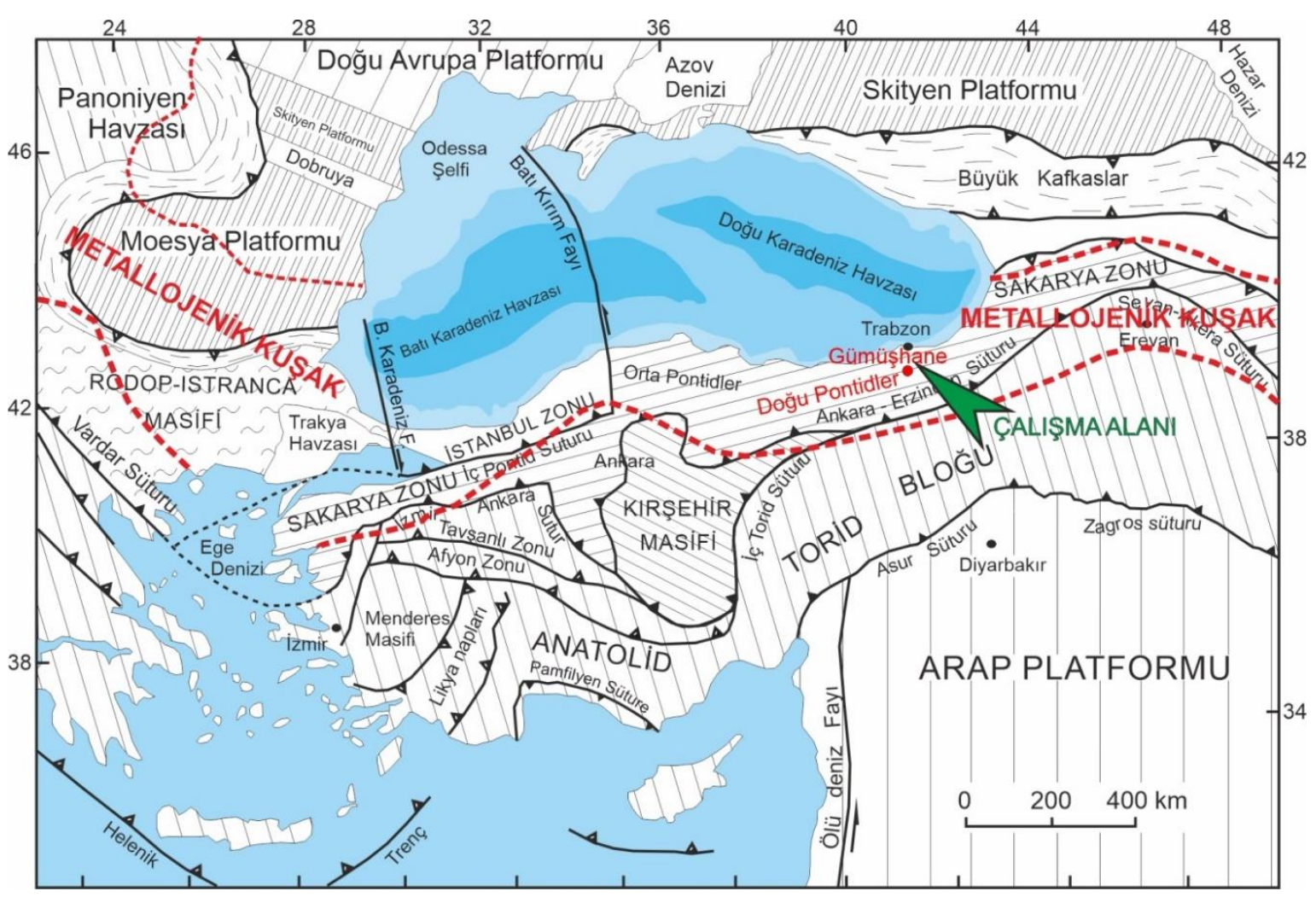

Şekil 1. Türkiye'nin tektonik haritası (Okay ve Tüysüz, 1999) ve çalışma alanının konumu.

Figure 1. Tectonic map of Turkey (Okay and Tüysüz, 1999) and the location of the study area.

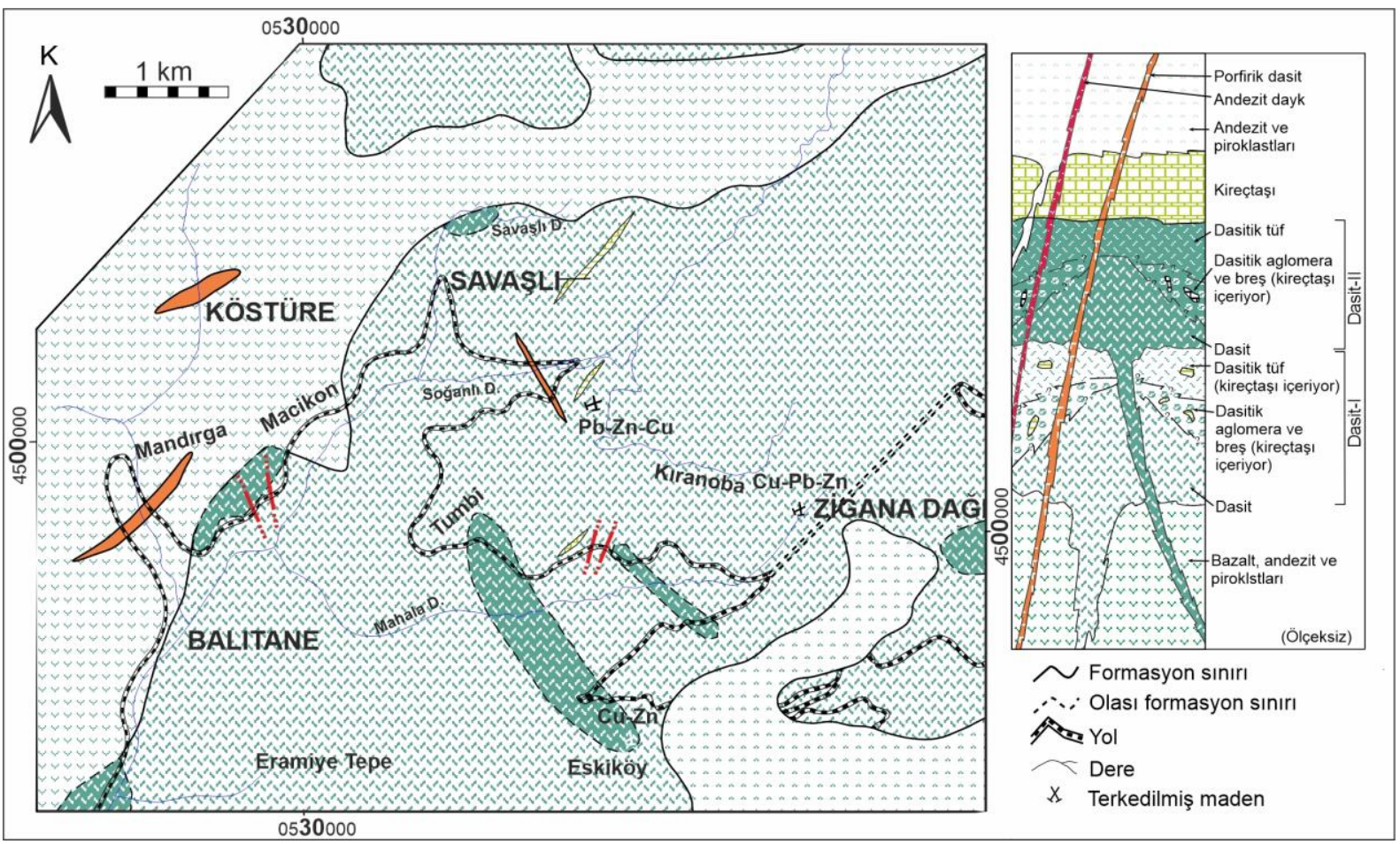

Şekil 2. İnceleme alanının detaylı jeoloji haritası ve stratigrafik kesiti (Sipahi, 2005).

Figure 2. Detailed geological map and stratigraphic column of the study area (Sipahi, 2005). 


\section{BULGULAR}

\section{Petrografi}

\section{Andezit daykları}

Andezitler Macikon ve Zigana Tüneli civarında mostra vermektedir (Şekil 2). Birim, arazide koyu yeşilimsi siyah renkleriyle tanınmakta ve dasitleri kesmekte olup, KB ve KD uzanımlı dayklar halinde görülmektedir (Şekil 3).

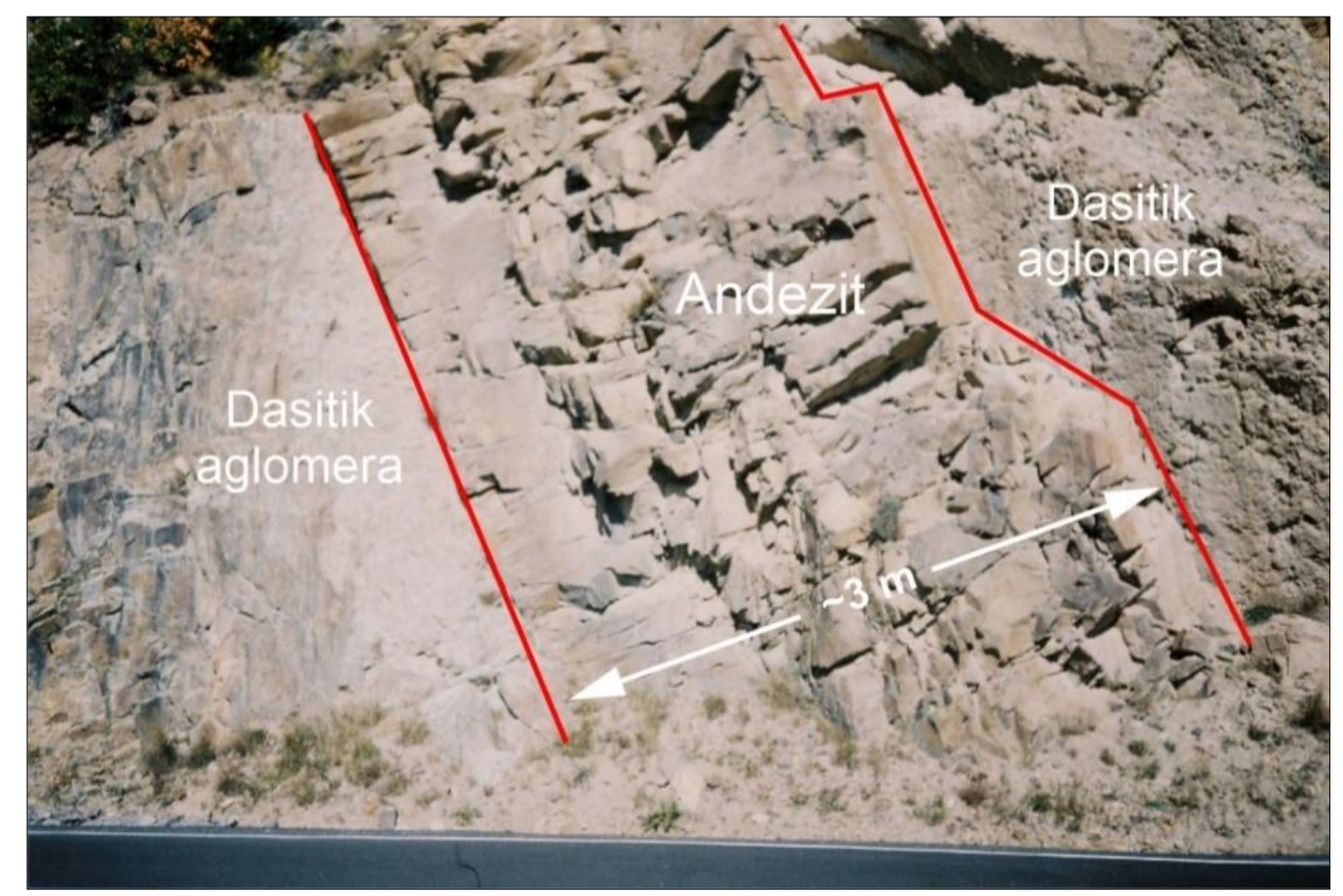

Şekil 3. Dasitik aglomeraları kesen andezit daykının arazideki görünümü.

Figure 3. Field photograph of an andesite dyke cutting through dacitic agglomerates.

Küçük kristalli porfirik, camsı ve elek dokularla karakterize olan dayklar, plajiyoklas ve ojit minerallerinden oluşmaktadır (Şekil 4). İkincil ürün olarak muskovit ve kuvars mineralleri gözlenmektedir. Öz ve yarı öz şekilli plajiyoklaslar hem iri kristaller hem de hamurda mikrolitler şeklinde bulunmaktadır. İri plajiyoklas kristalleri, minerallerin \% 50 65 'ini oluşturmakta olup, yaygın olarak serizitleşmiş (Şekil 4c), silisleşmiş ve daha az oranda kalsitleşmiştir. Bazı plajiyoklas kristallerinde polisentetik ikizlenmeler belirlenmiştir (Şekil 4b). Ojit mineralleri iri, öz ve yarı öz şekilli olarak bulunmakta ve iri kristallerin \% 30-40'nı oluşturmaktadır. Çoğunlukla kloritleşme ve kalsitleşme türünde 
ayrışma gösteren ojitlerin bazılarının etrafında opak mineral oluşumları bulunmaktadır (Şekil 4d). Ojitlerde ayrışma daha çok kırıklar boyunca gelişmiştir. Manyetit, pirit ve rutil opak mineralleri oluşturmaktadır (Şekil $4 \mathrm{~g}$ ve $4 \mathrm{~h}$ ). Rutil, manyetitlerin kenar ve kırıkları boyunca gelişmiştir. Andezitlerde genel olarak killeşme, serizitleşme, silisleşme, kloritleşme, hematitleşme, limonitleşme şeklinde ayrışma belirlenmiştir. Hacimsel açıdan kayacın \% 30-45'ini oluşturan hamur plajiyoklas, ojit ve opak minerallerden, bazen de volkan camından oluşmaktadır.

\section{Porfirik dasit daykları}

Porfirik dasitler, Balitane, Köstüre ve Savaşlı civarında mostra vermektedirler (bkz. Şekil 2). Hem bazalt ve andezitleri hem de dasitleri kesmekte olan bu dayklar, KB ve KD uzanımlı olup, kolonsu yapı gösterirler (Şekil 5). Porfirik dasitte ufak kristalli porfirik, camsı ve sferulitik dokular belirlenmiştir (Şekil 6). Mineral olarak en fazla kuvars ve plajiyoklas, daha az oranlarda amfibol, biyotit, muskovit ve pirit bulunmaktadır.

Kuvars, hem iri hem de hamurda küçük kristaller halinde, genellikle yarı öz şekilli ve öz şekilsiz olarak bulunmakta ve minerallerin \% 50-55'ini oluşturmaktadır. İri kuvars kristallerinin kenarları hamur tarafından kısmen yenmiştir (Şekil 6b, 6e ve 6f). Plajiyoklas, hem iri kristaller hem de hamurda mikrolitler şeklinde bulunmakta olup, iri plajiyoklas kristalleri minerallerin \% 45-50'sini meydana getirmektedir. Plajiyoklas minerallerinde yaygın olarak serizitleşme, daha az oranda kalsitleşme mevcuttur. Çoğunlukla iri, öz ve yarı öz şekilli olan amfiboller kloritleşmiş, karbonatlaşmış (kalsit ve ankerit) ve opaklaşmıştır (Şekil 6c). Biyotitlerde de amfibol minerallerinde olduğu gibi kloritleşmeler gözlenmektedir (Şekil 6a). Ayrıca, kloritler boşluk dolgusu şeklinde 

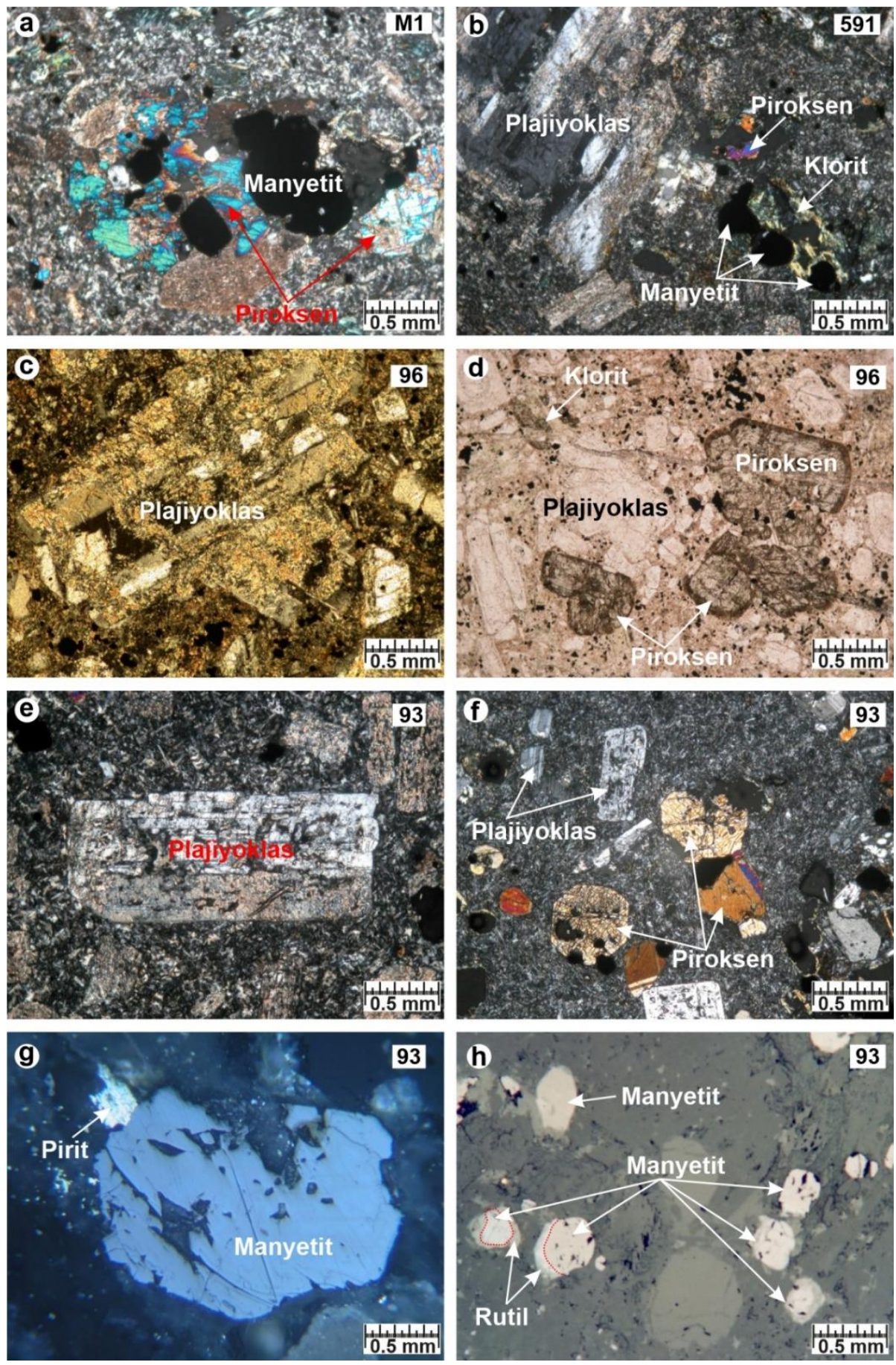

Şekil 4. Andezitik daykların mikroskop görünümleri. a) ve f) Mikrolitik porfirik doku (ÇN). b) Kloritleşmiş piroksen ve ayrışmış plajiyoklas minerali (ÇN). c) Glomerokristal dokulu serizitleşmiş plajiyoklas (ÇN). d) Camsı porfirik (hipokristalin) dokulu andezit (TN). e) Elek dokulu plajiyoklas fenokristali (ÇN). g) Manyetit ve pirit mineralleri (parlatılmış ince kesit) ve h) Manyetit ve kenarlarında rutil oluşumları (parlatılmış ince kesit).

Figure 4. Microphotographs of andesitic dykes. a) and f) Microlithic porphyritic textures (XN). b) Chloritized pyroxene and altered plagioclase mineral $(X N)$. c) Sericitized plagioclase with glomerocryst texture $(X N)$. d) Glassy porphyritic (hypocrystalline) texture in andesite (PPL). e) Plagioclase phenocryst with sieve texture $(X N)$. g) Magnetite and pyrite minerals (polished thin section), and h) Magnetite minerals and rutile formations around magnetite rims (polished thin section). 
ikincil kuvarslarla birlikte bulunmaktadır. Morumsu mavi renkte ve paralel sönme gösteren klorit minerallerinin mikroskobik özelliklerine göre pennin oldukları belirlenmiştir. Opak mineral olarak pirit ve hematit gözlemlenmiştir. Piritler genellikle kırıklı ve çatlaklı olup, kataklastik deformasyonun izlerini işaret etmektedir. Porfirik dasitlerde genel olarak serizitleşme, kloritleşme, silisleşme ve karbonatlaşma (kalsit ve ankerit) gibi ayrışmalar yaygındır. Hamur, küçük kristalli kuvars, plajiyoklas ve opak minerallerden oluşmakta ve kayacın toplam bileşen oranının \% 35-50'sini teşkil etmektedir.
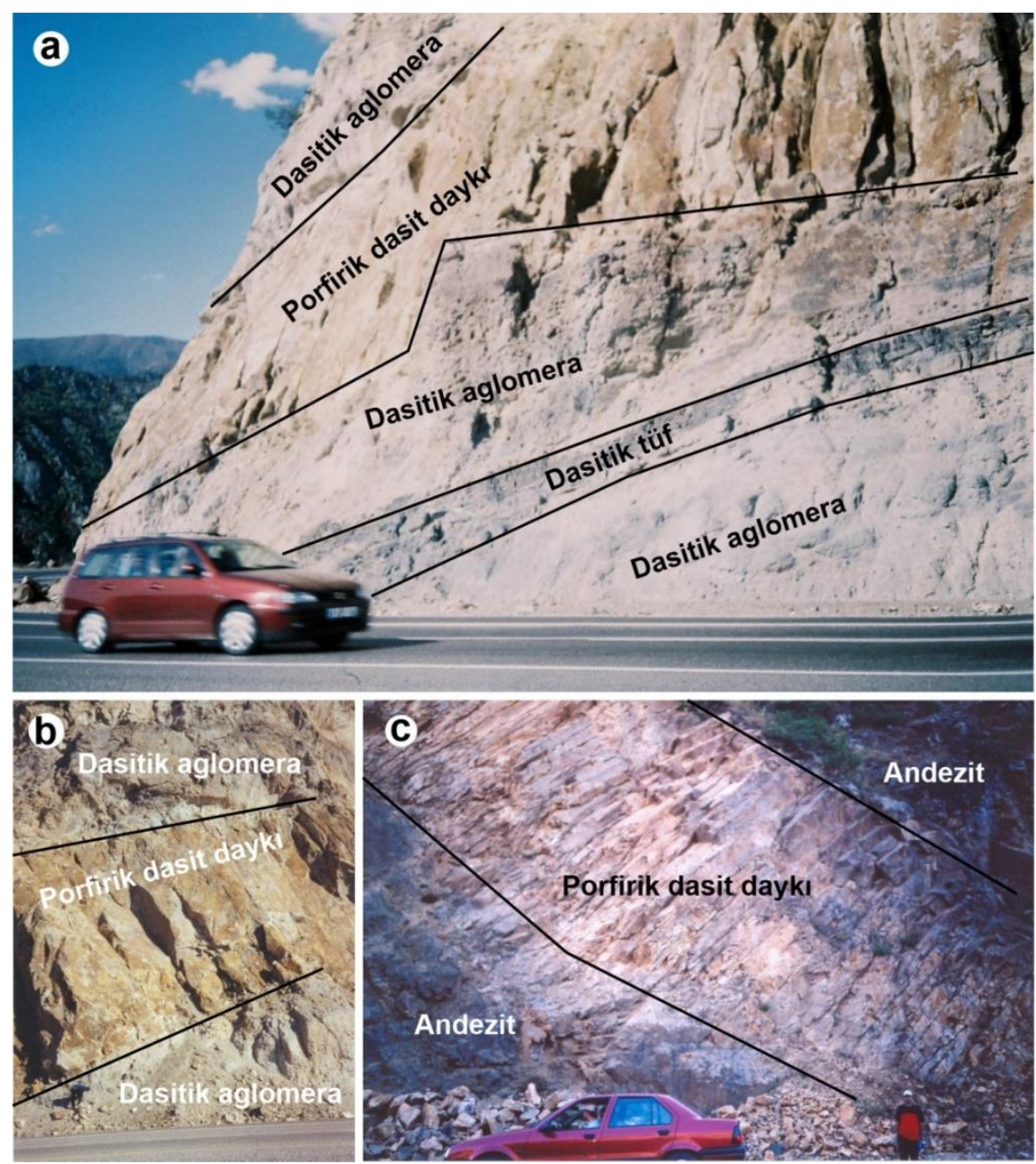

Şekil 5. Çalışma alanında a-b) dasitleri ve $c$ ) andezitleri kesen KB ve KD uzanımlı porfirik dasitlerin arazideki görünümleri.

Figure 5. Field photographs of porphyritic dacites extending in NW and NE directions, and cutting through (a-b) dacites and (c) andesites in the study area. 

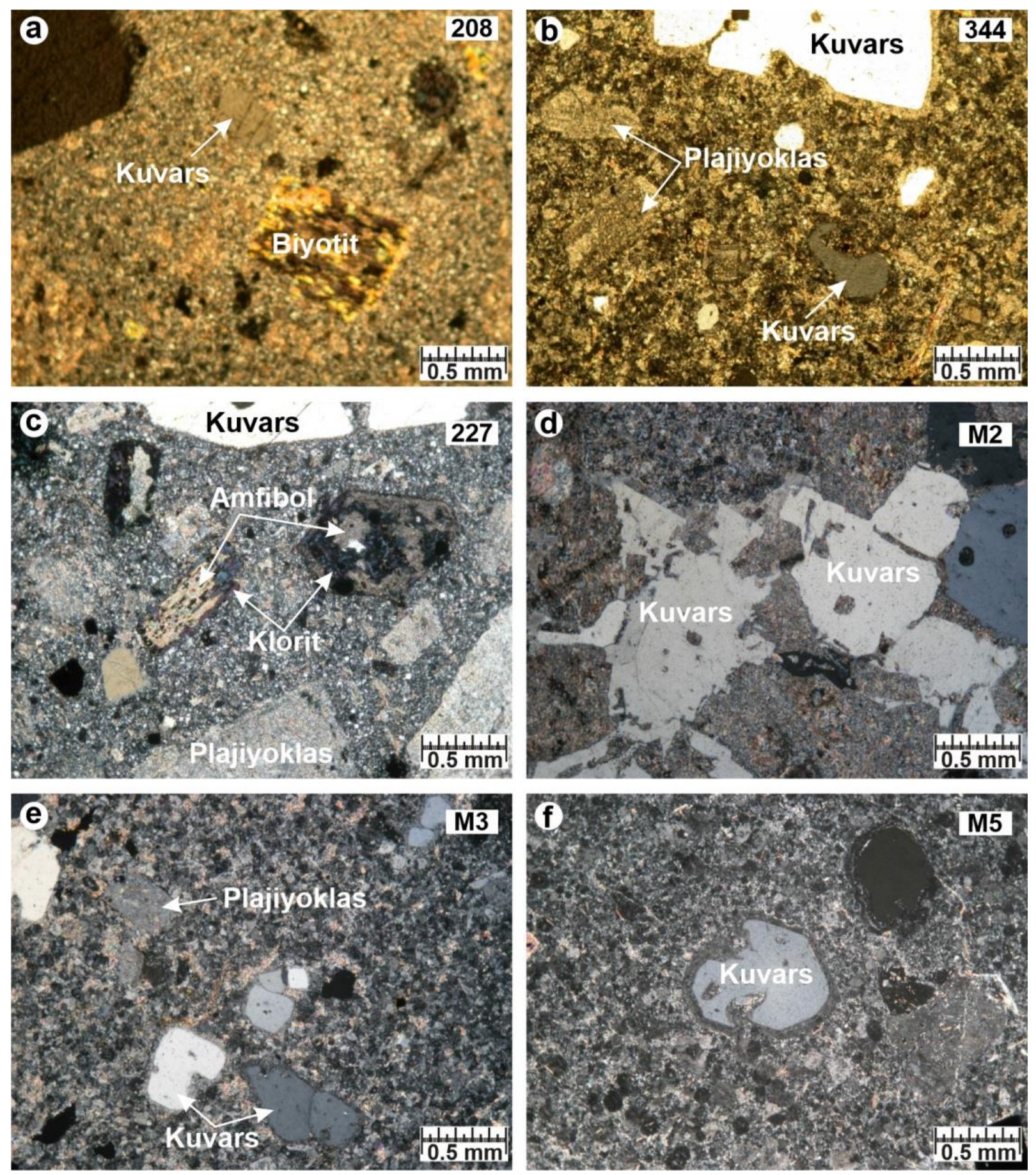

Şekil 6. Porfirik dasitlerin mikroskop görünümleri. a) ve b) Küçük kristalli porfirik doku (TN). c) Serizitleşmiş plajiyoklas ve kloritleşmiş amfibol minerali (ÇN). d), e) ve f) Kenarları yenmiş kuvars mineralleri (ÇN). e) ve f) Sferolitik doku ve kuvars etrafındaki tepkime haleleri (ÇN).

Figure 6. Microphotographs of porphyritic dacites. a) and b) Porphyritic texture with relatively small crystals (PPL). c) Sericitized plagioclase and chloritized amphibole minerals (XN). d, e and f) The embayed quartz crystals (XN). e) and f) Spherulitic texture with reaction halos around the quartz crystals $(X N)$. 


\section{Jeokimya}

Andezit ve porfirik dasitlerden alınan örneklerin ana ve iz element analizleri gerçekleştirilmiş ve sonuçlar Çizelge 1'de verilmiştir. Andezit ve porfirik dasit daykların adlandırılmasında $\mathrm{Nb} / \mathrm{Y}-\mathrm{Zr} / \mathrm{TiO}_{2}$ diyagramı (Winchester ve Floyd, 1977; Şekil 7) kullanılmış ve andezit dayklara ait tüm örnekler "andezit" alanında yer almıştır (Şekil 7). Porfirik dasit dayklarda ise, iki örnek andezit ve bir örnek trakiandezit alanına düşmüştür. Dayklardan alınan örneklerde, Huston (1993) tarafından geliştirilen İzokon Yöntemi kullanılarak yapılan kütle değişim hesaplamalarına (Sipahi, 2005) göre andezit alanına düşen örneklerde $\mathrm{Zr}$ azalması, trakiandezit alanında yer alan örnekte ise $\mathrm{Nb}, \mathrm{Zr}$ ve $\mathrm{Y}$ zenginleşmesi mevcuttur. Nb'daki zenginleşme $\mathrm{Y}^{\prime}$ un hemen hemen iki katı olduğundan, örnek trakiandezit alanında yer almıştır. Dolayısıyla, bu durum ilgili örneklerin aslında porfirik dasitlere ait olduğunu göstermektedir. Ayrıca mikroskop incelemeleri de bunların önemli miktarda kuvars içerdiğini ve porfirik dasit olarak adlandırılmasının daha uygun olacağını desteklemektedir.

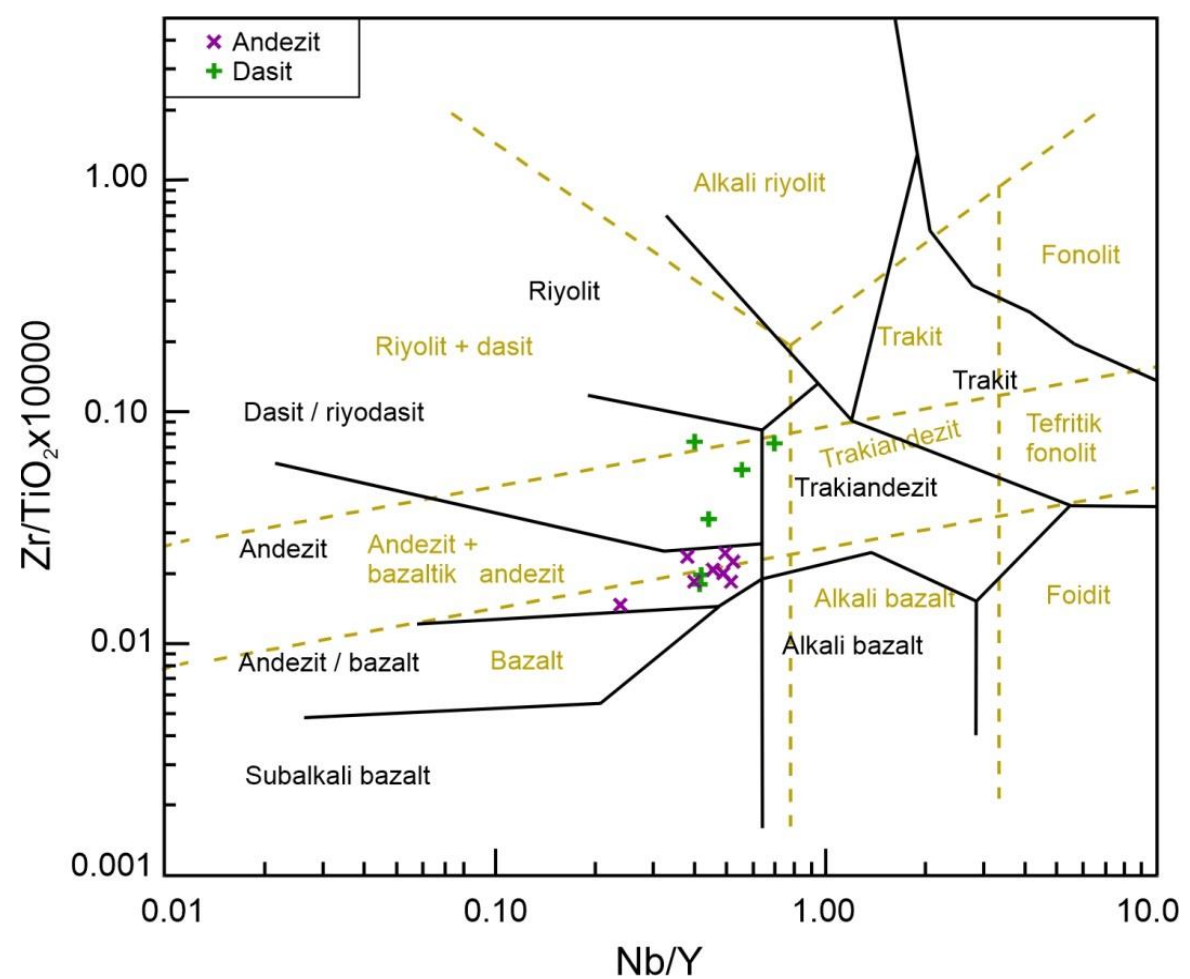

Şekil 7. Andezit ve porfirik dasit daykların $\mathrm{Nb} / \mathrm{Y}-\mathrm{Zr} / \mathrm{TiO}_{2}$ sınıflama diyagramı (Winchester ve Floyd, 1977'den değiştirilerek) kullanılarak adlandırılması. Kesikli çizgilerin oluşturduğu alanlar ve adlandırılmaları Pearce (1996)'dan alınmıştır.

Figure 7. $\mathrm{Nb} / \mathrm{Y}-\mathrm{Zr} / \mathrm{TiO} \mathrm{O}_{2}$ classification diagram of the andesite and porphyritic dacite dykes (after Winchester and Floyd, 1977). The classification fields formed by dashed lines and rock names are according to Pearce (1996). 
Andezitler jeokimyasal açıdan incelendiğinde, $\mathrm{P}_{2} \mathrm{O}_{5}$ 'e karşı $\mathrm{Zr}$ diyagramında (Şekil 8a) subalkali; Y'a karşı Zr diyagramında (Şekil 8b) ise, bir örnek hariç, kalk-alkali geçiş alanında yer almaktadır. Porfirik dasitler ise $\mathrm{P}_{2} \mathrm{O}_{5}$ 'e karşı $\mathrm{Zr}$ diyagramında (Şekil 8a) subalkali; Y'a karşı Zr diyagramında (Şekil 8b) ise kalk-alkali-geçiş alanına düşmektedir. Kütle değişim hesaplamalarına (Sipahi, 2005) göre, porfirik dasitler, iki örnek hariç, Y'ca zenginleşmiştir.
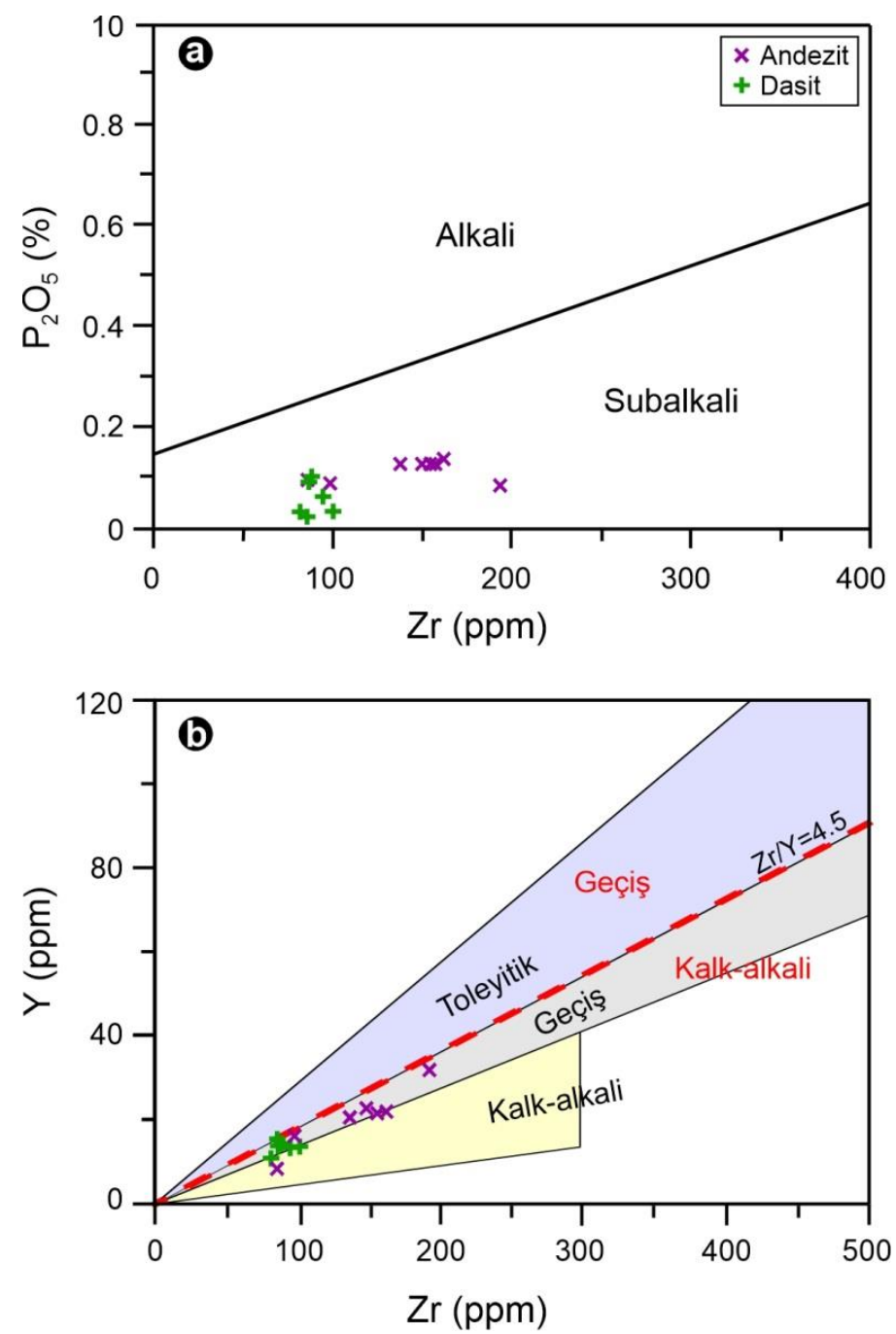

Şekil 8. Andezit ve porfirik dasit dayklarının jeokimyasal ayırtman diyagramları. a) $\mathrm{Zr}$ (ppm)'a karşı $\mathrm{P}_{2} \mathrm{O}_{5}$ (\%) alkali-subalkali ayırtman diyagramı (Winchester ve Floyd, 1976'dan değiştirilerek). b) Zr-Y sınıflama diyagramı (Barret vd., 1993). Kırmızı renkli kesikli kalk-alkali-geçiş çizgisi Ross ve Bédard, 2009'dan alınmıştır.

Figure 8. Geochemical discrimination diagrams for the andesite and porphyritic dacite dykes. a) $\operatorname{Zr}$ (ppm) vs. $\mathrm{P}_{2} \mathrm{O}_{5}(\%)$ plot distinguishing alkali from subalkali fields (after Winchester and Floyd, 1976). b) $\mathrm{Zr}$ vs. Y classification diagram of Barret et al. (1993). Red dashed line indicates the boundary between alkaline and calc-alkaline fields from Ross and Bédard (2009). 
Çizelge 1. Andezit ve porfirik dasit dayklarının ana (\% ağırlık), iz (ppm) ve nadir toprak element (ppm) analiz sonuçları.

Table 1. Results of major oxide (wt\%), trace (ppm) and rare earth (ppm) element analyses of andesite and porphyritic dacite dykes.

\begin{tabular}{|c|c|c|c|c|c|c|c|c|}
\hline \multicolumn{9}{|c|}{ Andezit dayk } \\
\hline Element $\backslash$ Örnek & 591 & DE1 & M1 & 588 & H & M4 & 93 & 96 \\
\hline \multicolumn{9}{|c|}{ Ana oksitler (\%) } \\
\hline $\mathrm{SiO}_{2}$ & 58.92 & 57.74 & 58.09 & 54.68 & 71.01 & 58.57 & 57.05 & 53.83 \\
\hline $\mathrm{TiO}_{2}$ & 0.57 & 0.61 & 0.63 & 1.02 & 0.38 & 0.66 & 0.61 & 0.66 \\
\hline $\mathrm{Al}_{2} \mathrm{O}_{3}$ & 17.28 & 15.51 & 15.90 & 20.90 & 13.87 & 15.90 & 16.56 & 16.97 \\
\hline${ }^{\mathrm{t}} \mathrm{Fe}_{2} \mathrm{O}_{3}$ & 6.37 & 6.74 & 7.01 & 11.81 & 2.76 & 6.89 & 7.45 & 8.04 \\
\hline $\mathrm{MnO}$ & 0.11 & 0.09 & 0.11 & 0.03 & 0.13 & 0.10 & 0.14 & 0.10 \\
\hline $\mathrm{MgO}$ & 4.68 & 3.84 & 4.29 & 0.93 & 1.52 & 3.82 & 3.70 & 3.79 \\
\hline $\mathrm{CaO}$ & 1.89 & 6.29 & 4.26 & 0.79 & 1.90 & 6.47 & 4.26 & 7.71 \\
\hline $\mathrm{Na}_{2} \mathrm{O}$ & 2.52 & 2.86 & 4.35 & 0.17 & 0.10 & 2.45 & 3.28 & 2.21 \\
\hline $\mathrm{K}_{2} \mathrm{O}$ & 4.05 & 3.19 & 2.98 & 5.82 & 3.94 & 2.67 & 3.56 & 1.78 \\
\hline $\mathrm{P}_{2} \mathrm{O}_{5}$ & 0.14 & 0.13 & 0.13 & 0.09 & 0.10 & 0.12 & 0.13 & 0.09 \\
\hline $\mathrm{CO}_{2}$ & 0.02 & 0.38 & 0.12 & 0.02 & a.e. & 0.11 & a.e. & a.e. \\
\hline AK & 3.06 & 2.24 & 1.73 & 3.41 & 3.93 & 1.70 & 2.46 & 4.78 \\
\hline Toplam & 99.61 & 99.62 & 99.60 & 98.88 & 99.64 & 99.46 & 99.20 & 99.96 \\
\hline \multicolumn{9}{|c|}{ İz (ppm) ve nadir toprak (ppm) elementler } \\
\hline As & 4.44 & 31 & 5.79 & 0.6 & 2 & 20 & 41 & 12 \\
\hline $\mathrm{Ba}$ & 771 & 763 & 561 & 1163 & 367 & 774 & 1058 & 419 \\
\hline $\mathrm{Ce}$ & 64.13 & 55.58 & 58.05 & 76.2 & 52 & 56.04 & 54.8 & 35.5 \\
\hline $\mathrm{Cl}$ & a.s.a & a.s.a. & a.s.a. & a.s.a. & $<10$ & a.s.a. & 17 & 26 \\
\hline Co & 17 & 16 & 14 & 13 & $<5$ & 21 & 19 & 20 \\
\hline $\mathrm{Cu}$ & 66 & 48 & 35 & 49 & 49 & 41 & 62 & 62 \\
\hline $\mathrm{Cr}$ & 19 & 12 & 18 & 6 & 22 & 25 & 24 & 43 \\
\hline Cs & 0.58 & 2.44 & 0.22 & 4.21 & 1.7 & 2 & 1.3 & 2.3 \\
\hline $\mathrm{Ga}$ & 15 & 12 & 13 & 19 & 19 & 12 & 16 & 19 \\
\hline $\mathrm{Hf}$ & 4.59 & 4.31 & 4.2 & 4.73 & 2.6 & 3.96 & 4.2 & 3 \\
\hline $\mathrm{Nb}$ & 11.12 & 10.33 & 9.82 & 16.1 & 7 & 8.92 & 9 & 4 \\
\hline $\mathrm{Ni}$ & 14 & 9 & 9 & 17 & $<5$ & 12 & 11 & 16 \\
\hline $\mathrm{Pb}$ & 26 & 19 & 16 & 6.27 & 16 & 24 & 24 & 78 \\
\hline $\mathrm{Rb}$ & 91 & 71 & 55 & 120 & 123 & 66 & 93 & 56 \\
\hline$S$ & 671.6 & 362 & 585.7 & 152 & 899 & 795 & 185 & 1057 \\
\hline $\mathrm{Sc}$ & a.e. & a.e. & a.e. & a.e. & 6 & a.e. & 16 & 25 \\
\hline $\mathrm{Sb}$ & 0.15 & 0.6 & a.s.a. & 0.45 & a.e. & 0.55 & a.e. & a.e. \\
\hline Sn & a.e. & a.e. & a.e. & a.e. & 3 & a.e. & 2 & 3 \\
\hline Sr & 247 & 241 & 233 & 76 & 14 & 261 & 344 & 176 \\
\hline $\mathrm{Ta}$ & 0.85 & 0.73 & 0.7 & 1.04 & 0.4 & 0.64 & 0.8 & 0.4 \\
\hline
\end{tabular}




\begin{tabular}{|c|c|c|c|c|c|c|c|c|}
\hline Th & 18.1 & 11.9 & 12.5 & 10.7 & 13 & 13.84 & 15 & 7 \\
\hline TI & a.e. & a.e. & a.e. & a.e. & 0.7 & a.e. & 0.3 & 0.7 \\
\hline$U$ & 5.56 & 4.51 & 4.42 & 2.13 & 10 & 4.05 & 8 & 4 \\
\hline V & 127 & 146 & 145 & 196 & 47 & 154 & 157 & 172 \\
\hline W & a.e. & a.e. & a.e. & a.e & 1 & a.e. & 3 & 1 \\
\hline $\mathrm{Zn}$ & 163 & 40 & 45 & 47.39 & 119 & 435 & 68 & 65 \\
\hline $\mathrm{Zr}$ & 131 & 123 & 130 & 181 & 131 & 119 & 156 & 99 \\
\hline Y & 21.38 & 21.39 & 21.62 & 31.7 & 8.1 & 22.38 & 20.1 & 16 \\
\hline La & 34.71 & 29.22 & 30.72 & 37.7 & 26 & 29.57 & 29 & 25 \\
\hline $\mathrm{Ce}$ & 64.10 & 55.60 & 58.10 & 76.20 & 37.50 & 56.00 & 54.80 & 35.50 \\
\hline $\operatorname{Pr}$ & 7.11 & 6.21 & 6.43 & 8.49 & 3.64 & 6.29 & 6.24 & 4.19 \\
\hline $\mathrm{Nd}$ & 25.10 & 23.00 & 23.30 & 33.00 & 12.20 & 23.40 & 23.80 & 16.50 \\
\hline Sm & 4.83 & 4.60 & 4.57 & 6.59 & 2.00 & 4.65 & 5.30 & 3.60 \\
\hline Eu & 1.10 & 1.04 & 0.993 & 1.47 & 0.51 & 1.07 & 1.12 & 0.86 \\
\hline $\mathrm{Gd}$ & 4.20 & 4.13 & 4.13 & 5.83 & 1.57 & 4.34 & 4.11 & 2.98 \\
\hline $\mathrm{Tb}$ & 0.631 & 0.644 & 0.613 & 0.896 & 0.22 & 0.639 & 0.56 & 0.43 \\
\hline Dy & 3.80 & 3.79 & 3.72 & 5.77 & 1.50 & 4.03 & 3.88 & 3.08 \\
\hline Ho & 0.777 & 0.743 & 0.754 & 1.17 & 0.30 & 0.778 & 0.80 & 0.64 \\
\hline Er & 2.29 & 2.32 & 2.31 & 3.46 & 0.97 & 2.36 & 2.30 & 1.97 \\
\hline $\mathrm{Tm}$ & 0.322 & 0.330 & 0.327 & 0.495 & 0.15 & 0.331 & 0.32 & 0.25 \\
\hline $\mathrm{Yb}$ & 2.32 & 2.23 & 2.25 & 3.34 & 1.21 & 2.29 & 2.25 & 1.77 \\
\hline Lu & 0.349 & 0.352 & 0.339 & 0.512 & 0.17 & 0.34 & 0.34 & 0.26 \\
\hline \multicolumn{9}{|c|}{ Hesaplamalar } \\
\hline $\mathrm{Mg}^{\#}$ & 74.42 & 69.29 & 70.82 & 23.73 & 68.56 & 68.71 & 66.30 & 65.10 \\
\hline KAI & 59.11 & 44.19 & 46.75 & 72.26 & 63.74 & 45.97 & 49.34 & 46.41 \\
\hline $\mathrm{Al}$ & 66.42 & 43.40 & 45.81 & 87.53 & 73.20 & 42.14 & 49.08 & 35.93 \\
\hline LAI & 1.68 & 1.75 & 1.54 & 2.12 & 1.05 & 2.08 & 1.62 & 2.94 \\
\hline$(\mathrm{La} / \mathrm{Lu})_{\mathrm{N}}$ & 10.33 & 8.62 & 9.41 & 7.64 & 12.95 & 9.03 & 8.76 & 6.91 \\
\hline$(\mathrm{La} / \mathrm{Sm})_{\mathrm{N}}$ & 4.52 & 4.00 & 4.23 & 3.60 & 6.67 & 4.01 & 3.41 & 3.02 \\
\hline$(G d / L u)_{N}$ & 1.50 & 1.46 & 1.52 & 1.42 & 1.15 & 1.59 & 1.51 & 1.43 \\
\hline$(\mathrm{Sm}+\mathrm{Gd})_{\mathrm{N}}$ & 34.65 & 33.38 & 33.30 & 47.59 & 13.79 & 34.29 & 36.38 & 25.32 \\
\hline $\mathrm{Eu}^{*}$ & 17.32 & 16.69 & 16.65 & 23.79 & 6.89 & 17.15 & 18.19 & 12.66 \\
\hline Eun & 12.62 & 11.96 & 11.41 & 16.85 & 5.86 & 12.29 & 12.87 & 9.89 \\
\hline $\mathrm{Eu}$ & 0.73 & 0.72 & 0.69 & 0.71 & 0.85 & 0.72 & 0.71 & 0.78 \\
\hline$(\mathrm{Tb} / \mathrm{Lu})_{\mathrm{N}}$ & 1.19 & 1.20 & 1.19 & 1.15 & 0.85 & 1.23 & 1.08 & 1.09 \\
\hline
\end{tabular}

AK: Ateşte kayıp, Mg\#: Mg numarası, KAl: Kimyasal ayrışma indeksi, Al: Ishikawa ayrışma indeksi, $\mathrm{L}_{\mathrm{Al}}$ : Lentz'in ayrışma indeksi, a.s.a.: Analiz sınırlarının altında, a.e.: Analiz edilmedi, $\mathrm{Eu}^{*}=\left(\mathrm{Sm}_{\mathrm{N}}+\mathrm{Gd} \mathrm{d}_{\mathrm{N}}\right) / 2, \mathrm{Eu}=\mathrm{Eu}_{\mathrm{N}} / \mathrm{Eu}^{*}$ 


\begin{tabular}{|c|c|c|c|c|c|c|}
\hline \multicolumn{7}{|c|}{ Porfirik dasit dayk } \\
\hline Element / Örnek & M2 & M3 & M5 & 344 & 208 & 227 \\
\hline \multicolumn{7}{|c|}{ Ana oksitler (\%) } \\
\hline $\mathrm{SiO}_{2}$ & 63.26 & 72.45 & 70.07 & 77.51 & 60.33 & 63.74 \\
\hline $\mathrm{TiO}_{2}$ & 0.27 & 0.14 & 0.14 & 0.12 & 0.45 & 0.50 \\
\hline $\mathrm{Al}_{2} \mathrm{O}_{3}$ & 16.92 & 17.56 & 16.04 & 13.31 & 17.50 & 16.74 \\
\hline${ }^{t} \mathrm{Fe}_{2} \mathrm{O}_{3}$ & 2.75 & 1.21 & 1.49 & 1.24 & 4.30 & 4.60 \\
\hline $\mathrm{MnO}$ & 0.08 & 0.02 & 0.04 & a.s.a. & 0.10 & 0.09 \\
\hline $\mathrm{MgO}$ & 0.85 & 0.55 & 1.11 & 0.29 & 2.21 & 1.85 \\
\hline $\mathrm{CaO}$ & 5.08 & 0.17 & 1.25 & 0.14 & 4.26 & 2.77 \\
\hline $\mathrm{Na}_{2} \mathrm{O}$ & 1.84 & 2.47 & 1.81 & 2.75 & 1.52 & 2.59 \\
\hline $\mathrm{K}_{2} \mathrm{O}$ & 3.97 & 3.82 & 4.45 & 3.48 & 3.63 & 3.86 \\
\hline $\mathrm{P}_{2} \mathrm{O}_{5}$ & 0.06 & 0.03 & 0.03 & 0.03 & 0.09 & 0.10 \\
\hline $\mathrm{CO}_{2}$ & 0.89 & 0.02 & 0.50 & a.e. & 0.83 & 0.35 \\
\hline AK & 3.73 & 1.54 & 2.41 & 1.30 & 4.47 & 2.74 \\
\hline Toplam & 99.70 & 99.98 & 99.74 & 100.14 & 99.69 & 99.93 \\
\hline \multicolumn{7}{|c|}{ İz (ppm) ve nadir toprak (ppm) elementler } \\
\hline As & 1.2 & 5.43 & 1.3 & 18 & 0.6 & 0.4 \\
\hline $\mathrm{Ba}$ & 470 & 306 & 1005 & 383 & 492 & 458 \\
\hline $\mathrm{Ce}$ & 40.5 & 48.3 & 70.9 & 47 & 40.9 & 41.7 \\
\hline $\mathrm{Cl}$ & a.s.a. & a.s.a. & a.s.a. & a.s.a & a.s.a. & a.s.a. \\
\hline Co & 3.7 & 0.7 & 0.5 & 5 & 7.8 & 8.3 \\
\hline $\mathrm{Cu}$ & 6.47 & 8.62 & 2.67 & 5 & 13 & 15 \\
\hline $\mathrm{Cr}$ & 2 & 7 & 1 & 8 & 34 & 17 \\
\hline Cs & 1 & 0.92 & 3.12 & 0.9 & 1.53 & 1.85 \\
\hline $\mathrm{Ga}$ & 12 & 11 & 12 & 10 & 15 & 15 \\
\hline $\mathrm{Hf}$ & 0.24 & 2.77 & 2.82 & 3.3 & 2.11 & 2 \\
\hline $\mathrm{Nb}$ & 5.75 & 5.74 & 10.15 & 6 & 5.6 & 5.87 \\
\hline $\mathrm{Ni}$ & 2.2 & 3.7 & 0.5 & a.s.a. & 6.8 & 6.7 \\
\hline $\mathrm{Pb}$ & 7.02 & 16.91 & 5.36 & 25 & 18 & 41 \\
\hline $\mathrm{Rb}$ & 108 & 97 & 89 & 123 & 92 & 103 \\
\hline$S$ & 1800 & 330 & 1340 & 300 & 870 & 240 \\
\hline $\mathrm{Sc}$ & a.e. & a.e. & a.e. & 3 & a.e. & a.e. \\
\hline $\mathrm{Sb}$ & a.s.a. & a.s.a. & 0.05 & a.e. & 0.35 & 0.25 \\
\hline $\mathrm{Sr}$ & 58 & 50 & 66 & 72 & 38 & 82 \\
\hline Ta & 0.52 & 0.73 & 0.97 & 0.9 & 0.56 & 0.56 \\
\hline Th & 10.7 & 19.8 & 20.9 & 22 & 13.7 & 11.5 \\
\hline
\end{tabular}




\begin{tabular}{|c|c|c|c|c|c|c|}
\hline $\mathrm{TI}$ & a.e. & a.e. & a.e. & 0.4 & a.e. & a.e. \\
\hline U & 4.36 & 5.6 & 5.33 & 10 & 4.22 & 3.22 \\
\hline V & 29 & a.s.a. & a.s.a. & 12 & 76 & 71 \\
\hline $\mathrm{Zn}$ & 49.75 & 36.95 & 24.27 & 20 & 64 & 64 \\
\hline $\mathrm{Zr}$ & 95 & 82 & 101 & 86 & 87 & 89 \\
\hline Y & 13.13 & 10.28 & 13.6 & 15 & 13.35 & 14.19 \\
\hline La & 23.76 & 27.15 & 39.4 & 23 & 22.4 & 23.48 \\
\hline $\mathrm{Ce}$ & 58.10 & 48.30 & 70.90 & 54.50 & 40.90 & 41.70 \\
\hline $\operatorname{Pr}$ & 6.43 & 4.63 & 7.07 & 5.34 & 4.26 & 4.45 \\
\hline $\mathrm{Nd}$ & 23.30 & 14.60 & 22.10 & 17.10 & 15.10 & 15.70 \\
\hline Sm & 4.57 & 2.38 & 3.38 & 2.70 & 2.90 & 3.10 \\
\hline Eu & 0.993 & 0.296 & 0.464 & 0.40 & 0.694 & 0.729 \\
\hline Gd & 4.13 & 1.76 & 2.46 & 2.15 & 2.54 & 2.71 \\
\hline $\mathrm{Tb}$ & 0.613 & 0.252 & 0.361 & 0.31 & 0.383 & 0.403 \\
\hline Dy & 3.72 & 1.61 & 2.25 & 2.05 & 2.39 & 2.48 \\
\hline Ho & 0.754 & 0.348 & 0.46 & 0.42 & 0.483 & 0.504 \\
\hline Er & 2.31 & 1.18 & 1.45 & 1.38 & 1.44 & 1.55 \\
\hline Tm & 0.327 & 0.195 & 0.227 & 0.22 & 0.206 & 0.225 \\
\hline $\mathrm{Yb}$ & 2.25 & 1.48 & 1.69 & 1.61 & 1.45 & 1.46 \\
\hline Lu & 0.339 & 0.235 & 0.255 & 0.27 & 0.22 & 0.225 \\
\hline \multicolumn{7}{|c|}{ Hesaplamalar } \\
\hline $\mathrm{Mg}^{\#}$ & 55.04 & 64.29 & 74.86 & 47.69 & 67.06 & 61.43 \\
\hline KAI & 50.52 & 67.38 & 61.45 & 60.87 & 55.25 & 55.40 \\
\hline Al & 41.06 & 62.35 & 64.46 & 56.28 & 50.28 & 51.53 \\
\hline $\mathrm{LAl}_{\mathrm{A}}$ & 0.61 & 0.28 & 0.41 & 0.24 & 1.26 & 1.00 \\
\hline$(\mathrm{La} / \mathrm{Lu})_{\mathrm{N}}$ & 10.45 & 11.99 & 16.01 & 11.65 & 10.58 & 10.86 \\
\hline$(\mathrm{La} / \mathrm{Sm})_{\mathrm{N}}$ & 6.37 & 7.19 & 7.33 & 7.06 & 4.87 & 4.77 \\
\hline$(\mathrm{Gd} / \mathrm{Lu})_{\mathrm{N}}$ & 1.08 & 0.93 & 1.20 & 0.99 & 1.44 & 1.50 \\
\hline$(\mathrm{Sm}+\mathrm{Gd})_{\mathrm{N}}$ & 16.86 & 16.04 & 22.67 & 18.71 & 20.84 & 22.27 \\
\hline $\mathrm{Eu}^{*}$ & 8.43 & 8.02 & 11.34 & 9.36 & 10.42 & 11.14 \\
\hline Eun & 6.69 & 3.40 & 5.34 & 4.60 & 7.97 & 8.37 \\
\hline $\mathrm{Eu}$ & 0.79 & 0.42 & 0.47 & 0.49 & 0.76 & 0.75 \\
\hline$(\mathrm{Tb} / \mathrm{Lu})_{\mathrm{N}}$ & 0.90 & 0.70 & 0.93 & 0.75 & 1.14 & 1.18 \\
\hline
\end{tabular}

AK: Ateşte kayıp, Mg\#: Mg numarası, KAl: Kimyasal ayrışma indeksi, Al: Ishikawa ayrışma indeksi, $L_{A l}$ : Lentz'in ayrışma indeksi, a.s.a.: Analiz sınırlarının altında, a.e.: Analiz edilmedi, $\mathrm{Eu}^{*}=\left(\mathrm{Sm}_{\mathrm{N}}+\mathrm{Gd}_{\mathrm{N}}\right) / 2, \mathrm{Eu}=\mathrm{Eu}_{\mathrm{N}} / \mathrm{Eu}^{*}$ 
edilmiştir (Şekil 9 ve 10). Bunun nedeni, daykların az veya çok oranda ayrışmış ve bu ayrışmanın silisleşme, serizitleşme, kloritleşme ve kaolinleşme şeklinde gelişmiş olmasıdır. Dolayısıyla, değişim diyagramları ayrışmanın etkisini en aza indirgemek için LAI indeksine göre oluşturulmuştur.

Ana element değişim çizgisellemelerinde LAl'ya karşı ${ }^{\mathrm{t}} \mathrm{Fe}_{2} \mathrm{O}_{3}, \mathrm{TiO}_{2}$ ve $\mathrm{Al}_{2} \mathrm{O}_{3}$ 'da pozitif; $\mathrm{MgO}, \mathrm{CaO}, \mathrm{P}_{2} \mathrm{O}_{5}, \mathrm{Na}_{2} \mathrm{O}$ ve $\mathrm{K}_{2} \mathrm{O}$ 'de ise düzensiz bir ilişki görülmektedir (Şekil 9). LA'ya karşı İz element değişim diyagramlarında ise, $Z r$ ve Th negatif, V, Sr ve Cs pozitif bir ilişki, diğerlerinde ise düzensiz bir ilişki gözlenmektedir (Şekil 10). Rb'un LAı'ne karşı gösterdiği ilişki $\mathrm{K}_{2} \mathrm{O}$ ile uyumludur. $\mathrm{L}_{\mathrm{Al}}$ değerinin artmasına karşılık $\mathrm{CaO}$ 'in düzensiz dağılımı, ayrışmanın etkisini göstermektedir. Andezitlerde, ince kesitte, ojit minerali tespit edilmiş olup, bu mineral ${ }^{\mathrm{t}} \mathrm{Fe}_{2} \mathrm{O}_{3}$ ve $\mathrm{MgO}$ artışını işaret etmektedir. Oysa andezitlerde LAine karşı oluşturulan MgO diyagramı incelendiğinde, az da olsa düzenli bir ilişki, ' $\mathrm{Fe}_{2} \mathrm{O}_{3}$ 'de ise pozitif bir ilişki mevcuttur. MgO'deki bu düzensiz değişim, bazı örneklerde piroksen mineralinin kloritleşmesi ile ilişkilidir. Sr'un pozitif korelasyonu ise CaO'inki ile uyumludur. Porfirik dasitlerde Laı'ne karşı oluşturulan ana element değişim diyagramlarında $\mathrm{MgO}, \mathrm{CaO},{ }^{\mathrm{t}} \mathrm{Fe}_{2} \mathrm{O}_{3}, \mathrm{P}_{2} \mathrm{O}_{5}, \mathrm{TiO}_{2}, \mathrm{Al}_{2} \mathrm{O}_{3}$ ve $\mathrm{AK}$ pozitif; $\mathrm{K}_{2} \mathrm{O}$ hemen hemen sabit, $\mathrm{Na}_{2} \mathrm{O}$ ve $\mathrm{SiO}_{2}$ 'de ise negatif bir ilişki görülmektedir (Şekil 9). İz element değişim diyagramlarında ise Th, Rb ve U'da negatif; V ve Ga'da pozitif; Sr, Nb, Y ve Zr'da hemen hemen sabit ve Ba'da ise düzensiz bir ilişki belirlenmiştir (Şekil 10). Porfirik dasitlerde LAi'nin artmasıyla $\mathrm{K}_{2} \mathrm{O}$ 'da bir değişiklik olmaması, bu kayaçlarda ayrışma ürünü olarak illit ve kaolinit mineralleri bulunduğunu ve dolayısıyla ayrışmanın etkisini işaret etmektedir.

Andezit dayklardaki mineral ayrımlaşmasını denetleyen faktörler için $\mathrm{Y}-\mathrm{Cr}$ ve $\mathrm{Zr}-\mathrm{TiO}_{2}$ değişimleri incelenmiştir (Şekil 11). Andezitlere ait $\mathrm{Y}$ ve $\mathrm{Cr}$ arasında negatif, $\mathrm{Zr}$ ve $\mathrm{TiO}_{2}$ arasında ise örneklerin çoğunda $\mathrm{Zr}$ artışına karşın TiO2 değişmezken, bazı örneklerde pozitif (Şekil 11b) bir ilişki mevcuttur. Porfirik dasitlerde ise $\mathrm{Y}-\mathrm{Cr}$ ve $\mathrm{Zr}$ - $\mathrm{TiO} 2$ arasındaki ilişki incelendiğinde, $\mathrm{Cr}$ artarken $\mathrm{Y}^{\prime}$ 'un ve $\mathrm{TiO}_{2}$ artarken $\mathrm{Zr}$ 'un sabit kaldığı görülmektedir. 

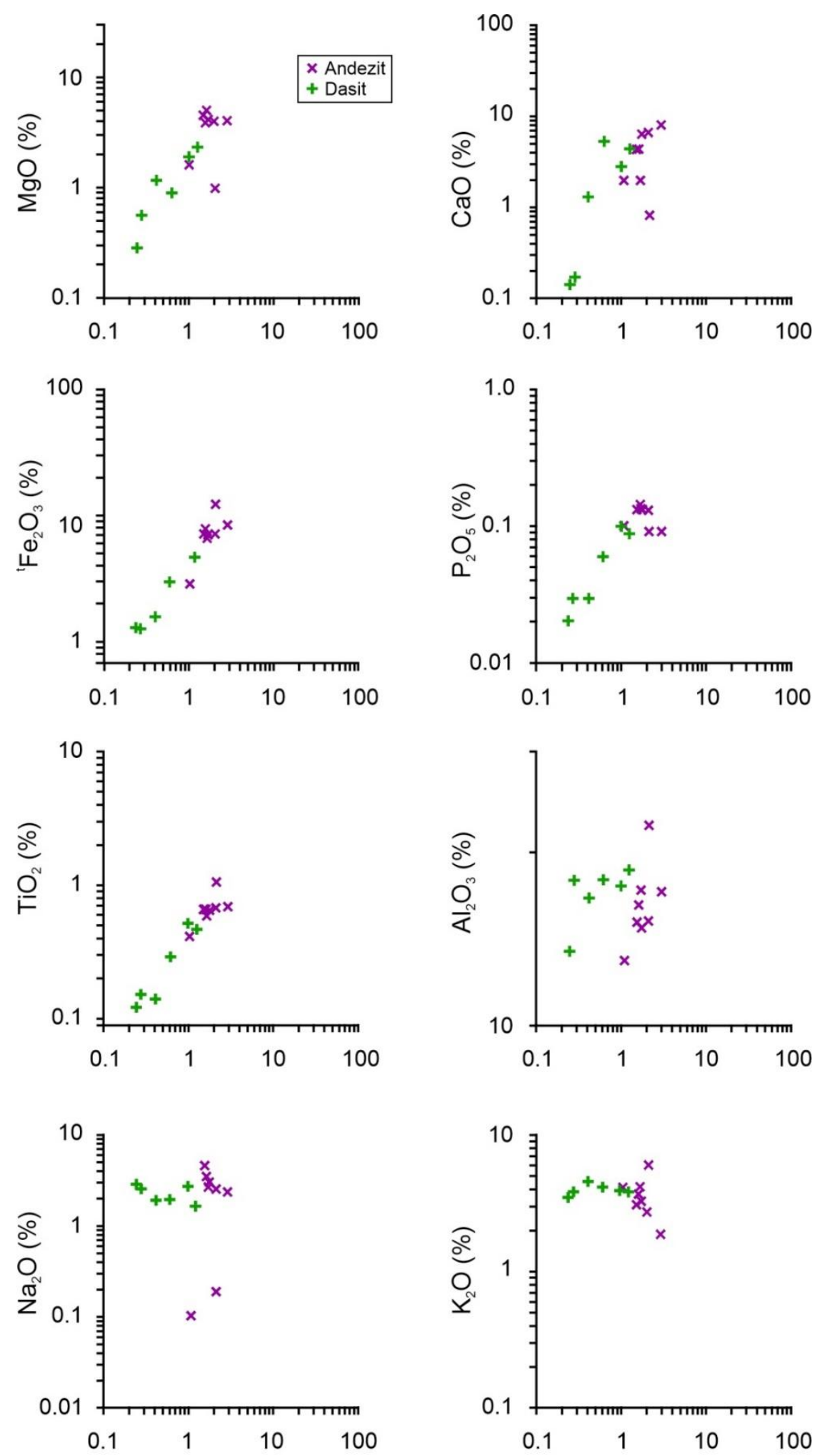

$$
\mathrm{L}_{\mathrm{Al}}=\left({ }^{\mathrm{t}} \mathrm{Fe}_{2} \mathrm{O}_{3}+\mathrm{MgO}\right) /\left(\mathrm{Na}_{2} \mathrm{O}+\mathrm{K}_{2} \mathrm{O}\right)
$$

Şekil 9. Andezit ve porfirik dasit dayklarında bazı ana oksitlerin (\%), $\mathrm{LAl}_{\mathrm{Al}}\left({ }^{\mathrm{t}} \mathrm{Fe}_{2} \mathrm{O}_{3}+\mathrm{MgO}\right) /\left(\mathrm{Na}_{2} \mathrm{O}+\mathrm{K}_{2} \mathrm{O}\right)$ oranına karşı değişim diyagramları.

Figure 9. Some major oxides (\%) vs $\mathrm{L}_{A 1}\left({ }^{t} \mathrm{Fe}_{2} \mathrm{O}_{3}+\mathrm{MgO}\right) /\left(\mathrm{Na}_{2} \mathrm{O}+\mathrm{K}_{2} \mathrm{O}\right)$ variation diagrams for the andesite and porphyritic dacite dykes. 
100
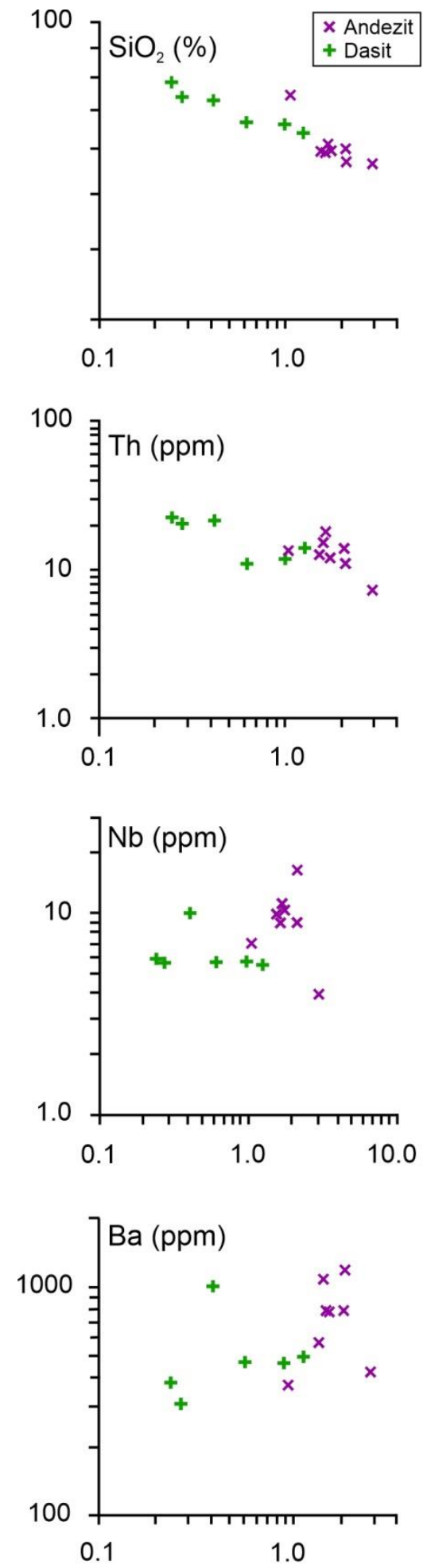
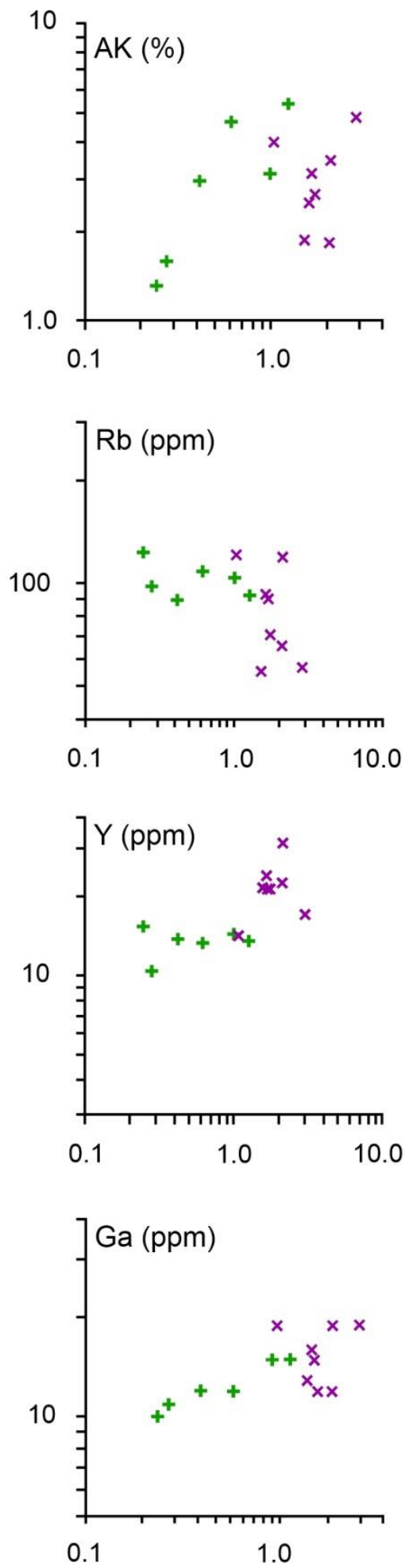
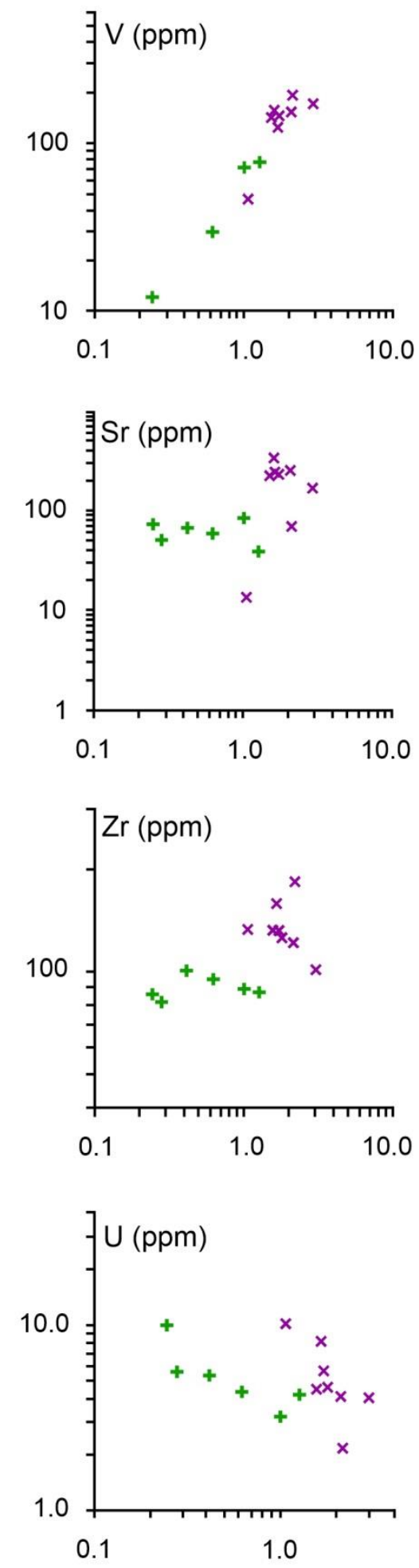

$\left({ }^{\mathrm{t}} \mathrm{Fe}_{2} \mathrm{O}_{3}+\mathrm{MgO}\right) /\left(\mathrm{Na}_{2} \mathrm{O}+\mathrm{K}_{2} \mathrm{O}\right)$

Şekil 10. Andezit ve porfirik dasit dayklarında bazı iz elementlerinin (ppm), $\left.\mathrm{LAI}^{(}{ }^{(} \mathrm{Fe}_{2} \mathrm{O}_{3}+\mathrm{MgO}\right) /\left(\mathrm{Na}_{2} \mathrm{O}+\mathrm{K}_{2} \mathrm{O}\right)$ oranına karşı değişim diyagramları.

Figure 10. Some trace elements (ppm) vs $\mathrm{L}_{A 1}\left({ }^{t} \mathrm{Fe}_{2} \mathrm{O}_{3}+\mathrm{MgO}\right) /\left(\mathrm{Na}_{2} \mathrm{O}+\mathrm{K}_{2} \mathrm{O}\right)$ variation diagrams for the andesite and porphyritic dacite dykes. 

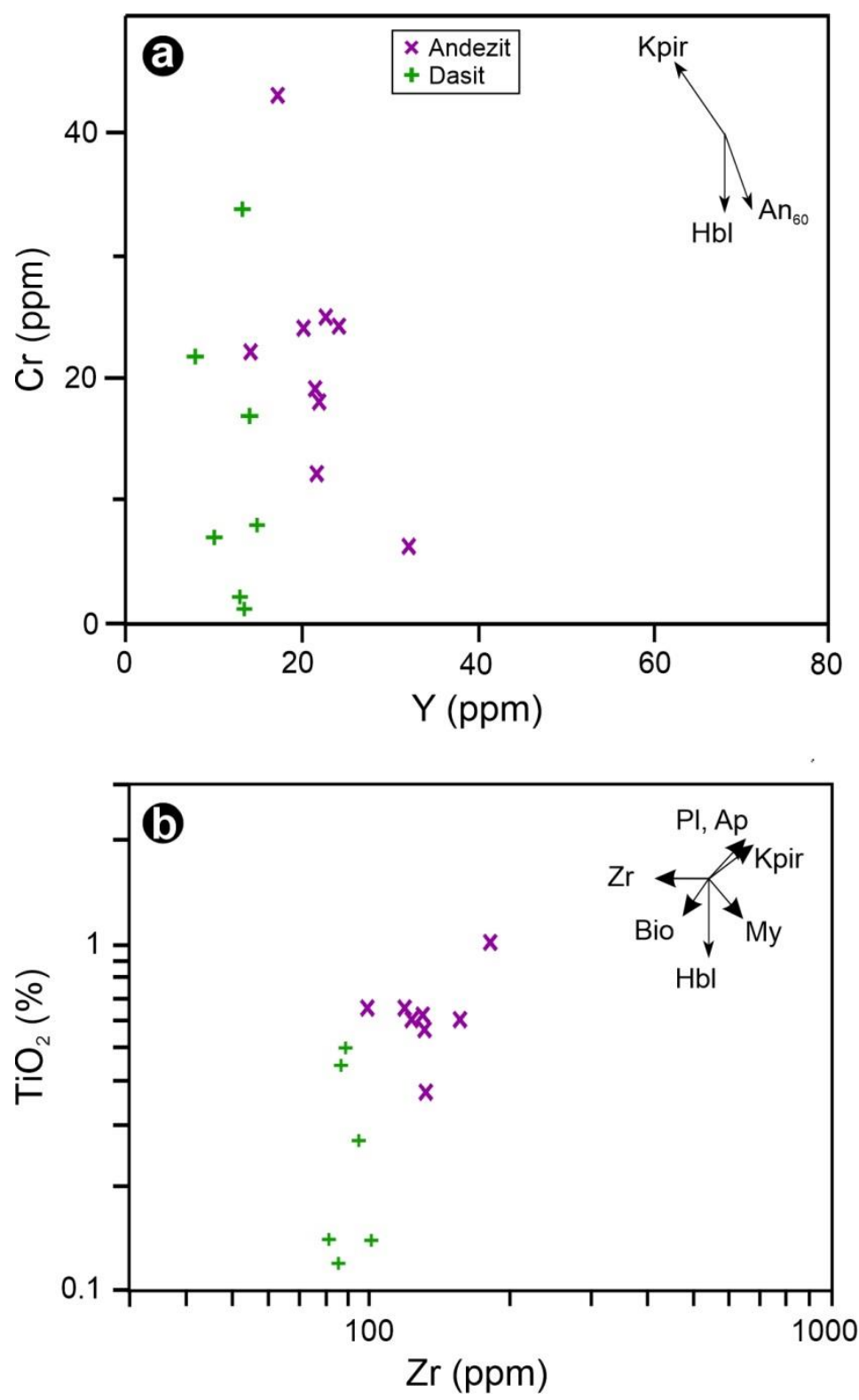

Şekil 11. Andezit ve porfirik dasit dayklarının mineral ayrımlaşma diyagramları. a) Y (ppm)'a karşı $\mathrm{Cr}$ (ppm) ve b) $\mathrm{Zr}$ (ppm)'a karşı $\mathrm{TiO}_{2}$ (\%) diyagramları. Mineral ayrımlaşma gidişatları Pearce ve Norry (1979)'dan alınmıştır.

Figure 11. Mineral discrimination diagrams for the andesite and porphyritic dacite dykes. a) $Y$ (ppm) vs $\mathrm{Cr}(\mathrm{ppm})$ and, b) $\mathrm{Zr}$ (ppm) vs $\mathrm{TiO}_{2}(\%)$ diagrams. Mineral differentiation trends are according to Pearce and Norry (1979).

Andezit ve porfirik dasit dayklarının iz ve nadir toprak element analiz sonuçları Çizelge 1'de verilmiş olup, bu kayaçlar Z-OOSB göre normalleştirilmiş ve uyumsuz element çizgisellemeleri oluşturulmuştur (Şekil 12). Andezit dayklarda, Z-OOSB'a göre BIYYE'lerce zenginleşme ve YÇAE'lerce fakirleşme söz konusudur. BIYYE'lerden (Sr, K, 
$\mathrm{Rb}$, Ba ve Th) özellikle Th'da, bazalt ve andezitlerde olduğu gibi, zenginleşme en yüksek değere ulaşmakta olup, $\mathrm{Sr}$ ve $\mathrm{K}_{2} \mathrm{O}$ 'de ise diğerlerine nazaran azalma görülmektedir. Sr'daki bu azalmanın plajiyoklas ayrımlaşmasından kaynaklanmış olabileceği düşünülmektedir. Z-OOSB'a göre genel olarak paralel bir dağılım sunan YÇAE (Ta'dan Yb'a kadar olan) çok az tüketilmiştir. Andezit dayklarda normalleştirme sonucu YÇAE'den Ce'da pozitif anomali; $\mathrm{Ta}, \mathrm{Nb}, \mathrm{P}$ ve Ti'da negatif anomali gözlenmektedir. Ayrıca Ta, Nb, Zr, Hf, Sm, Y ve Yb'un Z-OOSB çizgisine yaklaşık düz bir çizgi halinde paralellik gösterirken, $\mathrm{Sr}, \mathrm{K}, \mathrm{Rb}, \mathrm{Ba}$, Th ve Ce'da zenginleşme söz konusudur. Andezit dayklar yüksek BIYYE ve nispeten düşük YÇAE içeriklere sahip olup, yüksek BIYE/YÇAE oranları ile yitim ilişkili kayaçların tipik karakterlerini yansıtırlar. Andezit daykların BIYE zenginleşmesi ve gösterdikleri anomali değerleri ada yayı toleyitik volkanitlerinden fazla ve genel olarak KVK (kalk-alkali volkanik) yayların BIYE değişimlerine benzemektedir.

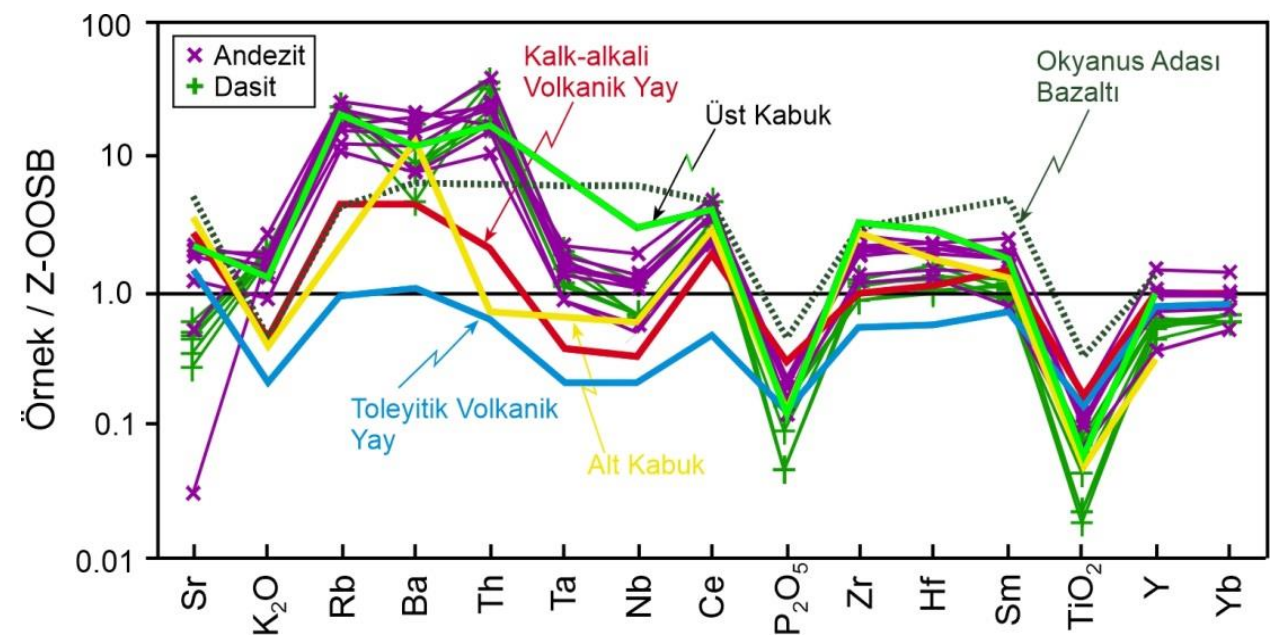

Şekil 12. Andezit ve porfirik dasit dayklarının Z-OOSB (zenginleşmiş okyanus ortası sırtı bazaltı; Sun ve McDonough, 1989)'ye göre normalize edilmiş uyumsuz element paternleri.

Figure 12. E-MORB (enriched mid-ocean ridge basalts; Sun ve McDonough, 1989) normalized immobile element patterns for the andesite and porphyritic dacite dykes.

Porfirik dasitler, Z-OOSB'ne göre normalleştirildiğinde BIYE'ce zenginleşme ve YÇAE'ce fakirleşme görülmesi söz konusudur (Şekil 12). BIYE (K, Rb, Ba ve Th)'lerden özellikle Rb ve Th'da zenginleşme en yüksek değere ulaşmaktadır. YÇAE (Ta'dan Yb'a kadar olan), $\mathrm{Ce}, \mathrm{P}_{2} \mathrm{O}_{5}$ ve $\mathrm{TiO}_{2}$ hariç, OOSB'na göre genel olarak paralel bir dağılım sunmakta ve buna göre çok az miktarda tüketilmiş olabileceğini göstermektedir. Porfirik dasitler yüksek BIYE ve düşük YÇAE içerikleri ve yüksek BIYYE/YÇAE oranları 
ile yitim ilişkili kayaçların karakteristik özelliklerini yansıtmaktadır. Bu kayaçlarda BİYE zenginleşmesi ve gösterdikleri anomali değerleri, ada yayı toleyitik ve kalk-alkali volkanitlerinden fazla, fakat dağılım şekli genel olarak kalk-alkali volkanik yaylardakine benzemektedir. Fakat kalk-alkali volkanik yaylardan daha fazla BiYE, Ta, Nb ve Ce zenginleşmesi göstermektedirler.

Andezit daykların nadir toprak elementleri (NTE) kondirite göre normalleştirilmiştir (Şekil 13). Andezit dayklar, LaN/LuN (7.64-12.95) oranlarına göre, az farklılaşmış ve az da olsa negatif Eu anomalisi göstermektedir. Ayrıca ağır nadir toprak element (ANTE) bakımından yataya yakın bir dağılım sunarlar (Şekil 13). Hafif nadir toprak element (HNTE) içeriği 45-100 x kondirit, ANTE içeriği 5-15 x kondirit arasında değişmektedir. $\mathrm{Bu}$ kayaçlarda ortalama Eu anomalisi 0.73 'dür. Porfirik dasitlerin nadir toprak elementleri (NTE) kondirite göre normalleştirilerek değişimleri verilmiştir (Şekil 13). Bu kayaçlarda LaN/Lun oranları 10.45-16.01 arasında değişmektedir. Ayrıca ağır NTE bakımından dasit porfirler yataya yakın bir dağılım sunmaktadır (Şekil 13). Hafif NTE içerikleri 61-107 x kondirit, ağır NTE içerikleri ise yaklaşık 6-7 x kondirit arasında değişmektedir.

\section{TARTIŞMA}

\section{Fraksiyonel Kristallenme}

Çalışma alanındaki andezit dayklarda $\mathrm{TiO}_{2}$ ve ${ }^{\mathrm{t}} \mathrm{Fe}_{2} \mathrm{O}_{3}$ 'in artması, manyetit ve rutil ayrımlaşmasını belirtirken (Şekil 9), $\mathrm{Na}_{2} \mathrm{O}$ ise daha çok ayrışmanın etkisini göstermektedir. LAı'ne göre Y ve Co'ın artması andezitlerin bünyesindeki ojitlerin varlığı ile desteklenmektedir (Şekil 10). Andezit dayklarda Cr'un artmasına karşılık Y'un azalması, klinopiroksen ve plajiyoklas ayrımlaşmasını işaret etmektedir (Şekil 11a). Zr ve $\mathrm{TiO}_{2}$ arasında pozitif ilişki (Şekil 11b), mineral vektörlerinden de anlaşılacağı gibi plajiyoklas, klinopiroksen, biyotit ve apatit ayrımlaşmalarına dikkat çekmektedir. 


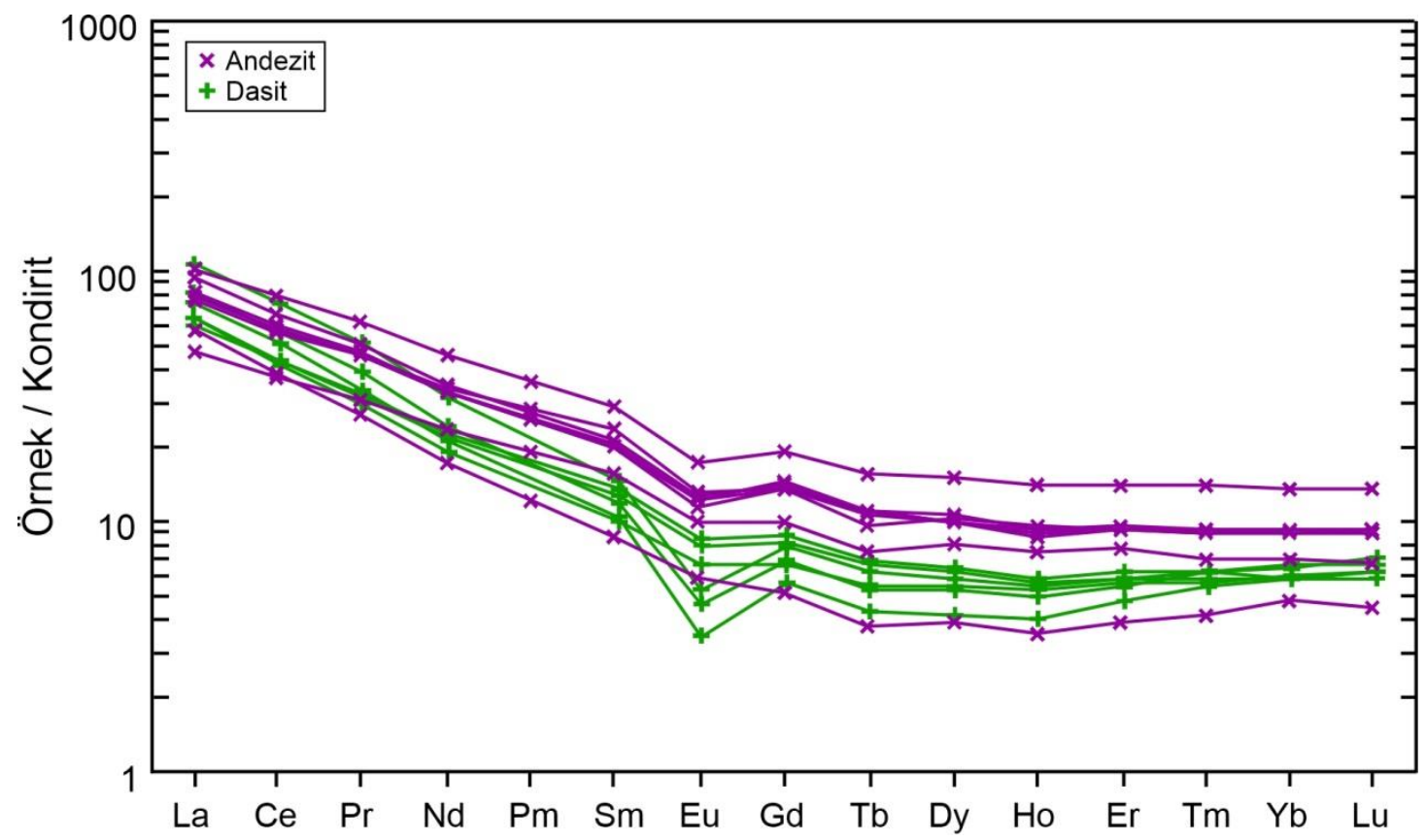

Şekil 13. Andezit ve porfirik dasit dayklarının kondirite (Taylor ve McLennan, 1985) göre normalleştirilmiş NTE dağııımları.

Figure 13. Chondrite (Taylor and McLennan, 1985) normalized REE diagram for the andesite and porphyritic dacite dykes.

Andezit dayklarda $\mathrm{Sr}, \mathrm{K}, \mathrm{Rb}, \mathrm{Ba}$, Th ve $\mathrm{Ce}$ gibi elementlerdeki zenginleşme, elementlerin yitim kökenli bir kaynaktan türediğini belirmektedir. Andezit dayklardaki negatif $\mathrm{Nb}$ anomalisi, kıtasal kabuğun $\mathrm{Nb}$ bakımından fakir olması nedeniyle, kabuksal kirlenmeden kaynaklanabilir. Çünkü negatif $\mathrm{Nb}$ anomalisi kıtasal kabuğun bir karakteristiğidir (Rollinson, 1993). Andezit dayklarda görülen negatif Eu anomalisi, düşük basınç ( $\leq 10 \mathrm{~kb}$ ) plajiyoklas ayrımlaşmasının ürünü olduğunu gösterebilir (Briggs ve McDonough, 1990). Andezit dayklar kondirite göre normalleştirildiğinde, HNTE değerlerinin artmakta, ANTE değerlerinin ise kondirit çizgisine paralel olduğu görülmektedir (Şekil 13). Bu dağılım, andezit daykların gelişiminde klinopiroksen ayrımlaşmasının etkili olduğuna işaret etmektedir (Nicholls ve Harris, 1980).

Porfirik dasit dayklarda $\mathrm{CaO}$ 'un artması plajiyoklas, $\mathrm{MgO}$ ve ${ }^{\mathrm{t}} \mathrm{Fe}_{2} \mathrm{O}_{3}$ 'in artması amfibol ve biyotit, $\mathrm{TiO}_{2}$ ve ${ }^{\mathrm{t}} \mathrm{Fe}_{2} \mathrm{O}_{3}$ 'in artması rutil, $\mathrm{P}_{2} \mathrm{O}_{5}$ 'in artması ise apatit ayrımlaşmasını göstermektedir (Şekil 9). LAI indeksi artıkça Ba'un düzensiz bir ilişki göstermesi ve Rb'un azalması porfirik dasitlerin bünyesinde K'lu feldispatların varlığı ve ayrışması ile 
desteklenmektedir (Şekil 10). Laı'ne göre Th ve U'daki negatif (veya $\mathrm{SiO}_{2}$ ile pozitif) ilişki bunların magmanın kristallenmesi esnasında ayrımlaştığını ve asitik kayaçlarda ve özellikle porfirik dasitlerde biriktiğini göstermektedir. Porfirik dasit dayklarda, LAI arttıkça $\mathrm{Sr}, \mathrm{Nb}, \mathrm{Y}$ ve $\mathrm{Zr}$ oranlarının sabit kalması, tamamen ayrışmadan kaynaklanmaktadır. Ayrıca, $\mathrm{Cr}-\mathrm{Y}$ ve $\mathrm{TiO}_{2}-\mathrm{Zr}$ arasındaki ilişki hornblend ayrımlaşmasını desteklemektedir (Şekil 11). Y, amfibol minerallerinin bünyesinde bulunmakta ve hareketsiz olarak bilinmektedir. Ancak Y'un kloritleşmiş ortamlarda hareketli olduğu da bilinmektedir (MacLean ve Kranidoitis, 1987; MacLean, 1990; Barrett ve MacLean, 1991; Barrett vd., 1992; Shriver ve MacLean, 1993; Barrett vd., 1993). Dolayısıyla, porfirik dasitlerde Y'un LAı arttıkça sabit kalması, amfibollerin bozuşması sonucu oluşan klorit+kuvars birlikteliğinin ve ayrışmaya bağlı olarak kayaçların kütlesinin artmasının veya azalmasının bir sonucudur.

Porfiri dasit dayklarda görülen negatif $\mathrm{Nb}$ anomalisi, kayaçların gelişiminde yitimin ve yitim zonu üzerindeki metazomatizmadan etkilenmiş manto kamasının önemli bir rol oynadığını gösterir (Pearce, 1982). Dolayısıyla, negatif $\mathrm{Nb}$ anomalisi yitim zonu ortamını yansıtmaktadır. YÇAE'in bir kısmında görülen zenginleşme, porfiri dasit daykların gelişiminde yitim ve yitim zonu üzerindeki metazomatizmadan etkilenmiş manto kamasının etkisini göstermektedir. Porfirik dasitlerde negatif Eu anomalisi gözlenmekte olup, ortalama Eu anomalisi 0.61 'dir. Negatif Eu anomalisi, düşük basınç ( $\leq 10$ kb) plajiyoklas ayrımlaşmasının ürünü olabilir (Briggs ve McDonough, 1990). Kondirite göre normalleştirilme sonucu, bu kayaçların hafif NTE (La, Ce Pr ve Nd) değerlerinin artması, orta (Sm, Eu, Gd, Tb, Dy ve Ho) ve ağır NTE (Er, Tm, Yb ve Lu) değerlerine göre daha fazladır. NTE'nin dağılım şekli (Şekil 13), bu kayaçların gelişiminde hornblend ile plajiyoklas ayrımlaşmasının etkili olduğunu belirtmektedir.

\section{Kabuk Kirlenmesi}

$\mathrm{Nb} / \mathrm{U}, \mathrm{La} / \mathrm{Nb}$ ve Th/Nb gibi iz element oranları, kıtasal kabuk materyalleri ve manto kökenli mafik magmaların güçlü zıt bileşimlerinden dolayı kabuk kirlenmesinin rolünü belirlemek için yaygın olarak kullanılmaktadır. Kıtasal kabuk düşük Nb/U (4.4-25) ile yüksek La/Nb (1.6-2.6) ve Th/Nb (0.24-0.88) oranlarına sahiptir (Rudnick ve Gao, 
2003). Okyanus adası bazaltı (OAB) ve okyanus ortası sırtı bazaltı (OOSB) ise yüksek $\mathrm{Nb} / \mathrm{U}(>45)$ ile düşük $\mathrm{La} / \mathrm{Nb}(0.8-1.1)$ ve $\mathrm{Th} / \mathrm{Nb}(<0.1)$ oranlarına sahiptir (Sun ve McDonough, 1989; Hollanda vd., 2006). Çalışma alanındaki andezit daykının, düşük $\mathrm{Nb} / \mathrm{U}(0.70-7.56)$ ile yüksek La/Nb (2.34-6.25) ve Th/Nb (0.66-1.86) oranlarına; porfirik dasit daykının düşük Nb/U (0.60-1.90) ile yüksek La/Nb (3.83-4.73) ve Th/Nb (1.863.67) oranlarına sahip olmaları kıtasal kabuk kirlenmesini işaret etmektedir.

\section{Olası Kaynak}

Çalışma alanındaki andezit ve porfirik dasit daykları Nb'a karşı $\mathrm{La}+\mathrm{Ce}$ ve $\mathrm{Zr}$ diyagramlarına aktarıldığında porfirik dasit daykı ile başlayan ve andezit daykı ile devam eden pozitif ilişki görülmektedir (Şekil 14a, 14b). Bu daykların element çiftleri arasında korelasyon ilişkisini gösteren çizginin yaklaşık olarak orijinden geçmesi, daykların benzer kökenli bir kaynaktan türediklerini işaret edebilir (Şekil 14a, 14b).
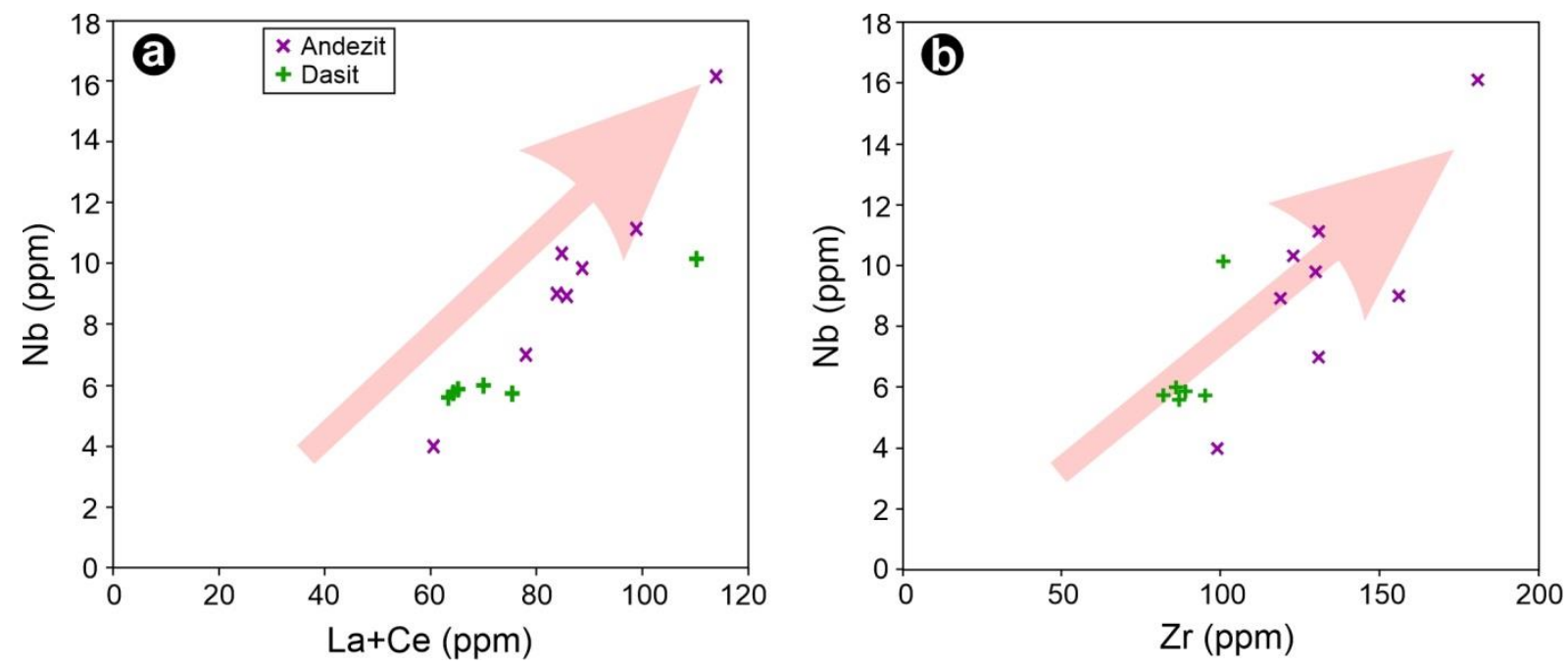

Şekil 14. Andezit ve porfirik dasit dayklarının a) La+Ce (ppm)'a karşı Nb (ppm) ve b) Zr (ppm)'a karşı $\mathrm{Nb}$ (ppm) değişim diyagramlarındaki dağııımları.

Figure 14. a) $\mathrm{La}+\mathrm{Ce}$ (ppm) vs $\mathrm{Nb}$ (ppm) and, b) $\mathrm{Zr}$ (ppm) vs Nb (ppm) diagrams for the andesite and porphyritic dacite dykes.

Andezit ve porfirik dasit daykları çeşitli tektonik ortam diyagramlarına aktarıldığında, volkanik yay granitoyidi (VYG) alanında yer aldıkları belirlenmiştir (Şekil 15a ve 15b). Çalışma alanındaki andezit dayklar, Zr'a karşı Ti (Pearce ve Cann, 1973) diyagramında kalk-alkali bazalt (KAB) alanına düşerken, porfirik dasit dayklar KAB 
alanında ve yakınında yer almaktadır (Şekil 15c). İnceleme alanındaki dayklar, Th/Yb karşı Ta/Yb diyagramında aktif kıta kenarları alanına denk gelmektedir (Şekil 15d).
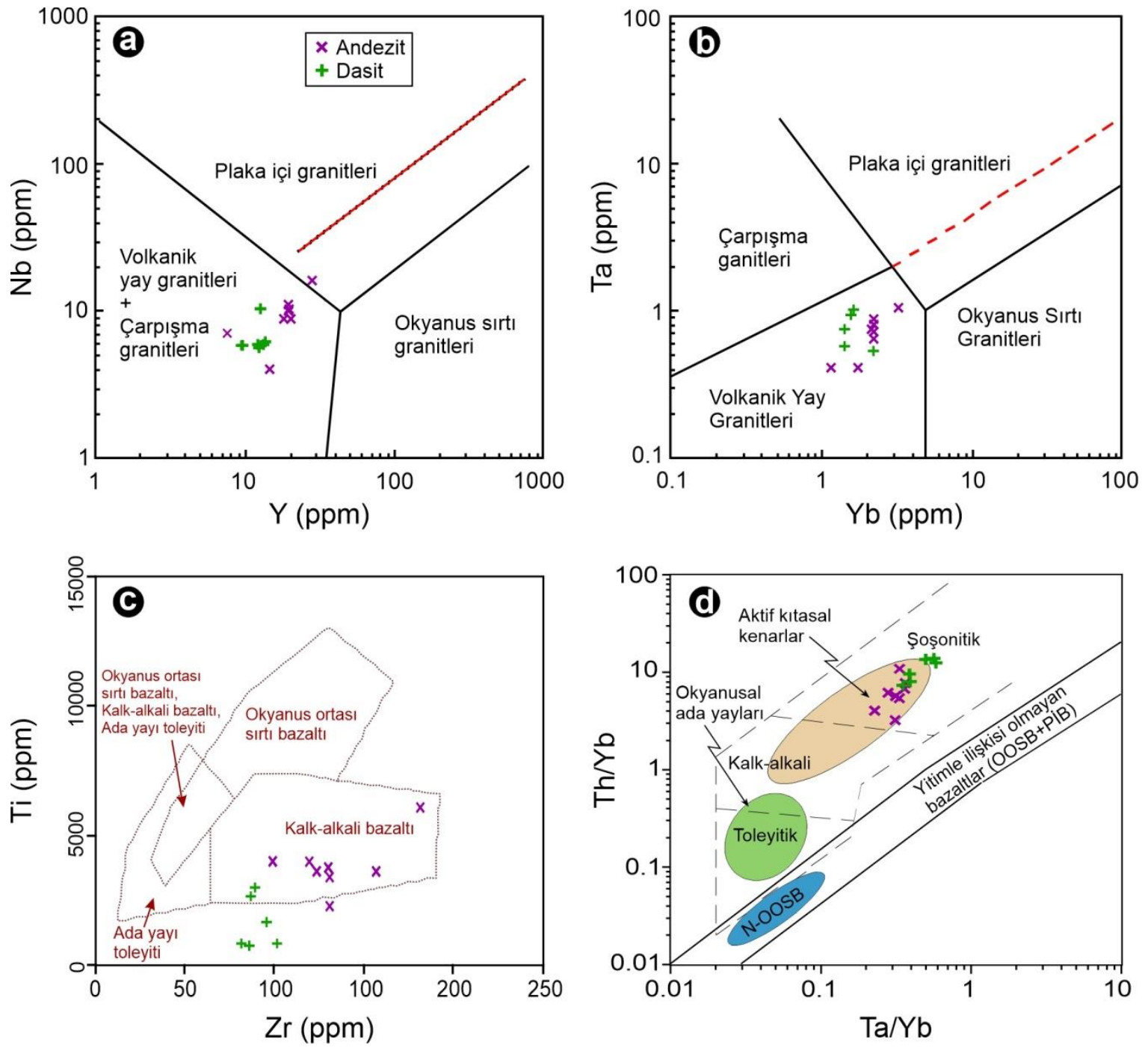

Şekil 15. Andezit ve porfirik dasit dayklarının çeşitli tektonik yerleşim diyagramlarındaki dağılımları.

Figure 15. Different tectonic discrimination diagrams for the andesite and porphyritic dacite dykes.

Çalışma alanındaki dayklardan andezitlerde $\mathrm{Zr} / \mathrm{Nb}$ (11.24-24.75), Zr/Y (5.32-16.17), $\mathrm{Nb} / \mathrm{Yb}$ (2.26-5.79) ve Ti/V (38.37-80.85) oranları Kitasal Kabuk (Rudnick ve Gao, 2003) $\mathrm{Zr} / \mathrm{Nb}$ (16.08-16.50), Zr/Y (6.95-9.19), Nb/Yb (4.21-6) ve Ti/V (50.40-65.98) oranlarına benzemektedir. Benzer şekilde, porfirik dasit daykının $\mathrm{Zr} / \mathrm{Nb}$ (9.95-16.52), $\mathrm{Zr} / \mathrm{Y}$ (5.73-7.98), Nb/Yb (2.56-6.01) ve Ti/V (59.21-100) oranları da kıtasal kabuk ve zenginleşmiş okyanus ortası sırtı bazaltına (Sun ve McDonough, 1989) benzemektedir. Hareketsiz uyumsuz element oranları, çalışma alanındaki daykların yitim ilişkili volkanik yay ortamından kaynaklandığını ileri sürmektedir. BíYE 
zenginleşmesi, zenginleşmiş alt kıtasal manto kaynağını göstermektedir. Ağır nadir toprak elementlere göre hafif nadir toprak element zenginleşmesi, BIYYE'lerce zenginleşme ve negatif $\mathrm{Nb}$ anomalisi yitim ilişkili ortamların karakteristik özelliğidir (Rocha-Junior vd., 2013). Ayrıca, sadece ayrımlaşma olayının değişmeyen uyumsuz element oranını koruyabildiği bilinmektedir (Innocenti vd., 1980). Çalışma alanındaki dayklarda yüksek Th ve U değerleri (andezitinde Th 7-18.1 ppm arasında ve U 2.1310 ppm arasında, porfirik dasitte Th 10.7-22 ppm arasında ve U 3.22-10 ppm), bunların yiten kabuk malzemesinin karışmasıyla zenginleşmiş bir manto kaynağından türediklerini ifade etmektedir (Faure ve Mensing, 2005). Daykların ANTE dağılımlarında görülen yatay yönseme, kayaçları oluşturan olası ana magmanın muhtemelen spinel lerzolitik $(<50 \mathrm{~km}$ derinlik $)$ bir manto kaynağından kaynaklanabileceğini ifade etmektedir. Dolayısıyla, çalışma alanındaki dayklar için Kretase yitim süresince metasomatize olmuş bir manto kaynağı olası olarak görülmektedir.

\section{SONUÇLAR}

Geç Kretase yaşlı volkanitleri kesen andezit ve porfirik dasit daykları porfirik doku sergilemekte olup, andezitler başlıca plajiyoklas ve ojit, porfirik dasitler ise kuvars, plajiyoklas, amfibol ve biyotit minerallerinden oluşmaktadır. Andezitlerdeki plajiyoklaslar elek dokusu ve polisentetik ikizlenme göstermektedir. Ojit minerallerinin kenar kısımlarında opak mineral oluşumları yaygındır. Porfirik dasitlerde, iri kuvars kristallerinin kenarları kısmen yenmiş; plajiyoklaslar yaygın olarak serizitleşmiş, daha az oranda kalsitleşmiş, amfiboller kloritleşmiş, karbonatlaşmış (kalsit ve ankerit) ve opaklaşmış, biyotitler ise genel olarak kloritleşmiştir.

Daykların ana oksit ve iz element değişim diyagramlarındaki düzgün yönsemeleri ve mineral ayrımlaşma diyagramları, kayaçların gelişiminde fraksiyonel kristalleşmenin etkili olduğunu işaret etmektedir. Daykların kondrite göre normalleştirilmiş NTE dağılımlarının belirgin negatif $\mathrm{Eu}$ anomali göstermesi, kayaçların gelişiminde plajiyoklas ayrımlaşmasının etkili olduğunu belirtmektedir. Andezit daykların gelişiminde plajiyoklas ve ojit, porfirik dasitlerin gelişiminde ise hornblend ve plajiyoklas ayrımlaşmasının etkili olduğu anlaşılmaktadır. Andezit daykının, düşük Nb/U ile yüksek $\mathrm{La} / \mathrm{Nb}$ ve Th/Nb oranlarına; porfirik dasit daykının düşük $\mathrm{Nb} / \mathrm{U}$ ile yüksek $\mathrm{La} / \mathrm{Nb}$ ve 
$\mathrm{Th} / \mathrm{Nb}$ oranlarına sahip olmaları, kıtasal kabuk kirlenmesini dikkat çekmektedir. Dayklardaki negatif Ta ve $\mathrm{Nb}$ anomalisi olası ana magma gelişiminde yitimin varlığını belirtmektedir.

Sonuç olarak, elde edilen tüm verilere göre daykların, yay ortamında, Geç Kretase sonlarına doğru benzer kökenli ve yitim ilişkili metasomatize olmuş bir manto kaynağından itibaren türemiş oldukları düşünülmektedir.

\section{KATKI BELIRTME}

Birinci sıradaki yazarın doktora çalışmasının bir bölümünü kapsayan bu çalışma, Karadeniz Teknik Üniversitesi Bilimsel Araştırma Fonu (BAP) tarafından 2001.112.005.1 nolu proje ile desteklenmiştir. Makalenin inceleme ve değerlendirme aşamasında yapmış oldukları katkılardan dolayı Baş Editör Prof. Dr. Mehmet Tekin YÜRÜR, Teknik Editör Dr. Gülbanu TEKBULUT ve hakemlere teşekkür ederiz.

\section{KAYNAKLAR}

Adamia, S.A., Lordkipanidze, M.B., Zakariadze, G.S., 1977. Evolution of an active continental margin as examplified by the Alpine history of Caucasus. Tectonophysics, 40, 183-199.

Akaryalı, E., Akbulut, K., 2016. Constraints of C-O-S isotope compositions and the origin of the Ünlüpınar volcanic-hosted epithermal $\mathrm{Pb}-\mathrm{Zn} \pm \mathrm{Au}$ deposit, Gümüşhane, NE Turkey. Journal of Asian Earth Sciences, 117, 119-134.

Akaryalı, E., 2016. Geochemical, fluid inclusion and isotopic (O, H and S) constraints on the origin of $\mathrm{Pb}-\mathrm{Zn} \pm \mathrm{Au}$ vein-type mineralizations in the Eastern Pontides Orogenic Belt (NE Turkey). Ore Geology Reviews, 74, 1-14.

Akıncı, Ö.T., 1984. The Eastern Pontide volcano-sedimentary belt and associated massive sulphide deposits. In: J.E. Dixon and A.H.F. Robertson (eds.), The Geological Evolution of the Eastern Mediterranean, Geological Society, London, Special Publications, 17, 415-428.

Arslan, M., Tüysüz, N., Korkmaz, S., Kurt, H., 1997. Geochemistry and petrogenesis of the eastern pontide volcanic rocks, Northeast Turkey. Chemie der Erde/Geochemistry, 57, 157-187. 
Aydın, F., Karslı, O., Chen, B., 2008. Petrogenesis of the Neogene alkaline volcanics with implications for post collisional lithospheric thinning of the Eastern Pontides, NE Turkey. Lithos, 104, 249-266.

Aydınçakır, E., 2014. The petrogenesis of Early Eocene non-adakitic volcanism in NE Turkey: Constraints on the geodynamic implications. Lithos, 208-209, 361-377.

Aydınçakır, E., 2016. Subduction-related Late Cretaceous high-K volcanism in the Central Pontides orogenic belt: Constraints on geodynamic implications, Geodinamica Acta, 28(4), 379-411.

Barrett, T.J., MacLean, W.H., 1991. Chemical, mass, and oxygen isotope changes during extreme hydrothermal alteration of an Archean rhyolite, Noranda, Quebec. Economic Geology, 86 (2), 406-414.

Barrett, T.J., Cattalani, S., MacLean, W.H., 1993. Volcanic lithogeochemistry and alteration at the Delbridge massive sulfide deposit, Noranda, Quebec. Journal of Geochemical Exploration, 48 (2), 135-173.

Barrett, T.J., Cattalani, S., Hoy, L., Riopel, J., Lafleur, P.-J., 1992. Massive sulfide deposits of the Noranda area, Quebec. IV. The Mobrun mine. Canadian Journal of Earth Sciences, 29, 1349-1374.

Bektaş, O., Pelin, S., Korkmaz, S., 1984. Doğu Pontid yay gerisi havzasında manto yükselimi ve polijenetik ofiyolit olgusu. TJK Ketin Sempozyumu, pp. 175-188.

Bektaş, O., Yılmaz, C., Taslı, K., Akdağ, K., Özgür, S., 1995. Cretaceous rifting of the eastern Pontide carbonate platform (NE Turkey): The formation of carbonates, breccias and turbidites as evidences of a drowned platform. Geologia, 57, 1-2, 233-244.

Briggs, R.M., McDonough, W.F., 1990. Contemporaneous Convergent Margin and Intraplate Magmatism, North Island, New Zealand. Journal of Petrology, 3 (14), 813-851.

Dokuz, A., 2011. A slab detachment and delamination model for the generation of Carboniferous high-potassium I-type magmatism in the Eastern Pontides, NE Turkey: Köse composite pluton. Gondwana Research, 19, 926-944.

Eyüboğlu, Y., Santosh, M., Yi, K., Tüysüz, N., Korkmaz, S., Dudas, F.O., Akaryalı, E., Bektaş, O., 2014. The Eastern Black Sea-type volcanogenic massive sulfide deposits: Geochemistry, zircon U-Pb geochronology and an overview of the geodynamics of ore genesis. Ore Geology Reviews, 59, 29-54.

Faure, G., Mensing, T.M., 2005. Isotope Principle and Applications. 3rd Edition, John Wiley \& Sons, Hoboken. 
Gücer, M.A., Aydınçakır, E., Yücel, C., Akaryalı, E., 2017. Tersiyer Yaşlı Altınpınar Hornblendli Andezitlerinin (Torul-Gümüşhane) Petrografisi, Mineral Kimyası ve P-T Kristalleşme Koşulları. Gümüşhane Üniversitesi, Fen Bilimleri Enstitüsü Dergisi, 7 (2), 236-267.

Hollanda, M.H.B.M., Pimentel, M.M., Oliveira, D.C., de Sá, E.F.J., 2006. Lithosphereasthenosphere interaction and the origin of Cretaceous tholeiitic magmatism in Northeastern Brazil: Sr-Nd-Pb isotopic evidence. Lithos, 86 (1-2), 34-49.

Huston, D.L., 1993. The Effect Of Alteration and Metamorphism on Wall Rock to the Balcooma and Dry River South Volcanic-Hosted Massive Sulfide Deposits, Queensland, Australia. Journal of Geochemical Exploration, 48, 277-307.

Innocenti, F., Mazzuoli, R., Pasquaré, G., Serri, G., Villari, L., 1980. Geology of the volcanic area north of Lake Van (Turkey). Geologische Rundschau, 69, 292-322. Kaygusuz, A., Arslan, M., Siebel, W., Sipahi, F., İlbeyli, N., 2012. Geochronological evidence and tectonic significance of Carboniferous magmatism in the southwest Trabzon area, eastern Pontides, Turkey. InternationalGeology Review, 54, 1776 1800.

Kaygusuz, A., Arslan, M., Siebel, W., Sipahi, F., İlbeyli, N., Temizel, İ., 2014. La-Icp Ms zircon dating and whole-rock $\mathrm{Sr}-\mathrm{Nd}-\mathrm{Pb}-\mathrm{O}$ isotope geochemistry of the Camiboğazı Pluton, eastern Pontides, NE Turkey: Petrogenesis and Tectonic Implications of Arc-Related I-Type Magmatism. Lithos, 192-195, 271-290.

Kaygusuz, A., Arslan, M., Sipahi, F., Temizel, İ., 2016. U-Pb zircon chronology and petrogenesis of carboniferous plutons in the northern part of the Eastern Pontides, NE Turkey: Constraints for Paleozoic magmatism and geodynamic evolution. Gondwana Research, 39, 327-346.

Kaygusuz, A., Sipahi, F., İlbeyli, N., Arslan, M., Chen, B., Aydınçakır, E., 2013. Petrogenesis of the Late Cretaceous Turnagöl intrusion in the eastern Pontides: implications for magma genesis in the arc setting. Geoscience Frontiers, 4, 423438.

Lentz, D.R., 1996. Trace-element systematics of felsic volcanic rocks associated with massive-sulphide deposits in the Bathurst Mining Camp: petrogenetic, tectonic and chemostratigraphic implications for VMS deposits. In: D.A. Wyman (ed.), Trace Element Geochemistry of Volcanic Rocks: Applications for Massive Sulphide Exploration, Geological Association of Canada, Short Course Notes 12, pp. 359-402.

Lentz, D.R., 1999. Petrology, geochemistry, and oxygen isotope interpretation of felsic volcanic rocks and related rocks hosting the Brunswick No. 6 and No. 12 massive 
sulfide deposits, Bathurst Mining Camp, New Brunswick, Canada. Economic Geology, 94, 57-86.

MacLean, W.H., Kranidiotis, P., 1987. Immobile elements as monitors of mass transfer in hydrothermal alteration: Phelps Dodge massive sulfide deposit, Matagami, Quebec. Economic Geology, 82, 951-962.

MacLean, W.H., 1990. Mass changes in altered rock series. Mineralium Deposita, 25, 44-49.

Nicholls, I.A., Harris, K.L., 1980. Experimental rare earth element partition coefficients for garnet, clinopyroxene and amphibole coexisting with andesitic and basaltic liquids. Geochimica et Cosmochimica Acta, 44 (2), 287-308.

Okay, A.I. , Tüysüz, O., 1999. Tethyan Sutures of Northern Turkey. The Mediterranean Basin: Tertiary Extension within the Alpine Orogen. Geological Society, London, Special Publications, 156, 475-515.

Özsayar, T., Pelin, S., Gedikoğlu, A., 1981, Doğu Pontidler'de Kretase: KTÜ Yerbilimleri Dergisi, 1, 2, 65-114.

Pearce, J.A., Norry, M.J., 1979. Petrogenetic Implication of Ti, Zr, Y and Nb Variations in Volcanic Rocks. Contributions to Mineralogy and Petrology, 69, 33-47.

Pearce, J.A., 1982. Trace Element Characteristics of Lavas from Destructive Plate Boundaries. In: Thorpe, R.S. (ed.), Andesites, Orogenic Andesites and Related Rocks. Wiley and Sons, Chichester, 525-548.

Pearce, J.A., 1996. A User's Guide to Basalt Discrimination Diagrams. In: Wyman, D.A. (ed.) Trace Element Geochemistry of Volcanic Rocks: Applications for Massive Sulphide Exploration. Geological Association of Canada, Short Course Notes 12, 79-113.

Pearce, J.A., Cann, J.R., 1973. Tectonic Setting of Volcanic Rocks Determined Using Trace Element Analyses. Earth and Planetary Science Letters, 19, 290-300.

Pejatoviç, S., 1979. Metallogeny of the pontid-type massive sulphide deposits, mineral geochemistry of massive sulphide-associated hydrothermal sediments of the Brunswick horizon, bathurst mining camp, New Brunswick, Canadian Journal of Earth Sciences, 33, 252-283.

Rocha-Júnior, E.R.V., Marques, L.S., Babinski, M., Nardy, A.J.R., Figueiredo, A.M.G., Machado, F.B., 2013. Sr-Nd-Pb isotopic constraints on the nature of the mantle sources involved in the genesis of the high-Ti tholeiites from northern Paraná 
continental flood basalts (Brazil). Journal of South American Earth Sciences, 46, 9-25.

Rollinson, H.R., 1993. Using Geochemical Data: Evaluation, Presentation, Interpretation. Johnn Wiley \& Sons, New York, $352 \mathrm{p}$.

Ross, P.-S., Bédard, J.H., 2009. Magmatic affinity of modern and ancient subalkaline volcanic rocks determined from trace-element discriminant diagrams. Canadian Journal of Earth Sciences, 46 (11), 823-839.

Rudnick, R.L.,, Gao, S., 2003. Composition of the continental crust. In: Rudnick, R.L. (ed.), The crust. Treatise on Geochemistry, 3, 1-64.

Saydam Eker, Ç., Sipahi, F., Kaygusuz, A., 2012. Trace and Rare Earth Elements as Indicators of Provenance and Depositional Environments of Lias Cherts in Gumushane NE Turkey. Chemie der Erde, 72, 167-177.

Shriver, N.A., MacLean, W.H., 1993. Mass, volume and chemical changes in the alteration zone at the Norbec mine, Noranda, Quebec. Mineralium Deposita, 28 (3), 157-166.

Sipahi, F., Sadıklar, M.B., 2010. The alteration mineralogy and mass change of the Zigana(Gümüşhane) volcanics of NE Turkey. Geological Bulletin of Turkey, 53, 122-155.

Sipahi, F., Sadıklar, M.B., 2014. Geochemistry of dacitic volcanics in the eastern Pontides (NE Turkey). Geochemistry International, 4, 329-349.

Sipahi, F., 2005. Zigana dağı (Torul-Gümüşhane) volkanitlerindeki hidrotermal ayrışmaların mineraloji ve jeokimyası, Doktora Tezi, KTÜ Fen Bilimleri Enstitüsü, Trabzon.

Sipahi, F., 2011. Formation of skarns at Gümüşhane (Northeastern Turkey). Neues Jahrb Mineral Abh (J. Min. Geochem.), 188, 169-190.

Sipahi, F., 2017. Kalınçam (Tonya-Trabzon, KD Türkiye) yöresi Geç Kretase yaşlı volkanitlerin jeokimyası ve petrojenezi. GÜFBED/GUSTIJ, 7 (2), 102-127.

Sipahi, F., 2019. Nature of the Tourmaline in Q-Porphyry from Eastern Pontide (NE Turkey): An U-Pb zircon Age, Geochemistry and Isotopic Approach. Periodico di Mineralogica, 88, Doi: 10.2451/2019PM859.

Sipahi, F., Akpınar, I., Saydam Eker, Ç., Kaygusuz, A., Vural, A., Yılmaz, M., 2017. Formation of the Eğrikar (Gümüşhane) Fe-Cu skarn type mineralization in NE Turkey: U-Pb zircon age, lithogeochemistry, mineral chemistry, fluid inclusion, 
and O-H-C-S isotopic compositions. Journal of Geochemical Exploration, 182, Part A, 32-52.

Sipahi, F., Kaygusuz, A., Saydam Eker, Ç., Vural, A., Akpınar, I.,, 2018. Late Cretaceous Arc Igneous Activity: The Eğrikar Monzogranite Example. International Geology Review, 60, 382-400.

Sipahi, F., Sadıklar, M.B., Şen, C., 2014. The geochemical and Sr-Nd isotopic characteristics of Murgul (Artvin) volcanics in the Eastern Black Sea Region (NE Turkey). Chemie der Erde/Geochemistry, 74, 331-342.

Sun, S., McDonough, W.F., 1989. Chemical and isotopic systematics of oceanic basalts: implications for mantle composition and processes. In: A.D. Saunders and M.J. Norry (eds.), Magmatism in the Ocean Basins. Geological Society, London, Special Publications, 42, 313-345.

Şengör, A.M.C., Yılmaz, Y., 1981. Tethyan evolution of Turkey: a plate tectonic approach, Tectonophysics, 75, 181-241.

Taylor, S.R., McLennan, S.M., 1985. The Continental Crust: Its Composition and Evolution. Blackwell Scientific Publications, Blackwell, Oxford, U.K., 312 p.

Temizel, I.., Arslan, M., Ruffet, G., Peucat, J.J., 2012. Petrochemistry, geochronology and Sr-Nd isotopic systematics of the Tertiary collisional and post-collisional volcanic rocks from the Ulubey (Ordu) area, eastern Pontide, NE Turkey: implications for extension-related origin and mantle source characteristics. Lithos, 128-131, 126-147.

Winchester, J.A., Floyd, P.A., 1977. Geochemical discrimination of different magma series and their differentiation products using immobile elements. Chemical Geology, 20, 325-343.

Winchester, J.A., Floyd, P.A., 1976. Geochemical magma type discrimination: Application to altered and metamorphosed basic igneous rocks. Earth and Planetary Science Letters, 28, 459-469. 